https://helda.helsinki.fi

Obesity and eating behavior from the perspective of twin and genetic research

\title{
Silventoinen, Karri
}

2020-02

Silventoinen , K \& Konttinen , H 2020 , ' Obesity and eating behavior from the perspective of twin and genetic research ' , Neuroscience \& Biobehavioral Reviews , vol. 109 , pp. 150-165 . https://doi.org/10.1016/j.neubiorev.2019.12.012

http://hdl.handle.net/10138/313345

https://doi.org/10.1016/j.neubiorev.2019.12.012

unspecified

publishedVersion

Downloaded from Helda, University of Helsinki institutional repository.

This is an electronic reprint of the original article.

This reprint may differ from the original in pagination and typographic detail.

Please cite the original version. 
Review article

\title{
Obesity and eating behavior from the perspective of twin and genetic research
}

\author{
Karri Silventoinen $^{\mathrm{a}, \mathrm{b}, *}$, Hanna Konttinen ${ }^{\mathrm{a}}$ \\ ${ }^{a}$ Department of Social Research, University of Helsinki, Helsinki, Finland \\ ${ }^{\mathrm{b}}$ Department of Public Health, University of Helsinki, Helsinki, Finland
}

\section{A R T I C L E I N F O}

\section{Keywords:}

Twins

Genetics

Obesity

BMI

Eating behavior

\begin{abstract}
A B S T R A C T
Obesity has dramatically increased during the last decades and is currently one of the most serious global health problems. We present a hypothesis that obesity is a neuro-behavioral disease having a strong genetic background mediated largely by eating behavior and is sensitive to the macro-environment; we study this hypothesis from the perspective of genetic research. Genetic family and genome-wide-association studies have shown well that body mass index (BMI, $\mathrm{kg} / \mathrm{m}^{2}$ ) is a highly heritable and polygenic trait. New genetic variation of BMI emerges after early childhood. Candidate genes of BMI notably express in brain tissue, supporting that this new variation is related to behavior. Obesogenic environments at both childhood family and societal levels reinforce the genetic susceptibility to obesity. Genetic factors have a clear influence on macro-nutrient intake and appetiterelated eating behavior traits. Results on the gene-by-diet interactions in obesity are mixed, but emerging evidence suggests that eating behavior traits partly mediate the effect of genes on BMI. However, more rigorous prospective study designs controlling for measurement bias are still needed.
\end{abstract}

\section{Introduction}

Obesity is one of the most serious current health problems. Health risks related to excess body weight were mentioned as far back as the Hippocratic texts (Haslam, 2007), but the association between obesity and increased mortality was shown for the first time in the early $20^{\text {th }}$ century based on US insurance statistics (Joint Committee on the Medico-Acturial Mortality Investigation, 1995, orig. 1912), a result which has been well confirmed in further studies (Flegal et al., 2013). Epidemiological studies have convincingly demonstrated that obesity is associated not only with multiple diseases such as type 2 diabetes (Vazquez et al., 2007), coronary heart disease (Marinou et al., 2010), musculoskeletal diseases (Paulis et al., 2014) and several cancers (Vucenik and Stains, 2012) but also an increased risk of disability retirement (Neovius et al., 2008) and low self-esteem (Griffiths et al., 2010). Obesity was estimated to globally be among the 5 most important risk factors of disability-adjusted life years in 2015; the increase has been rapid, since in 1990 it was not even among the 30 most important risk factors (GBD 2015 Risk Factors Collaborators, 2016). In addition to severe and in many cases life threatening health consequences to individuals, both direct and indirect costs to society are very high (Withrow and Alter, 2011). Since losing weight is extremely difficult because of several physiological and psychological mechanisms preventing weight loss (Langeveld and DeVries, 2015), preventing obesity is important.

The oldest and still most commonly used indicator of obesity is body mass index (BMI), which is calculated as weight in kilograms divided by the square of height in meters $\left(\mathrm{kg} / \mathrm{m}^{2}\right)$. This index was first proposed by Adolphe Quetelet in 1835 and was known previously as the Quetelet Index (Quetelet, 1994, orig. 1842). For newborns, the ponderal index using height cubed as the denominator $\left(\mathrm{kg} / \mathrm{m}^{3}\right)$ is usually recommended since it takes into account the body shape of the newborn better. The limitations of BMI at the individual level are, however, obvious since it does not discriminate between muscle and fat mass and tells nothing about fat distribution. Since visceral fat is metabolically more active and more strongly associated with metabolic diseases than subcutaneous fat (Wajchenberg, 2000), it has been suggested that other anthropometric indicators, especially waist circumference as it is considered a measure of visceral fat located in the abdominal cavity, should be used (Janssen et al., 2004). This is especially the case in epidemiological studies, which do not allow for use of direct measures of body composition such as computer tomography, dual-energy X-ray absorptiometry or even a much less expensive bioelectrical impedance method (Hu, 2008). In light of this evidence, it may be surprising that at the population level BMI correlates very highly with other obesity indicators and also does well at predicting the cardiometabolic traits (Bell

\footnotetext{
* Corresponding author at: Department of Social Research, University of Helsinki, P.O. Box 18, FIN-00014, University of Helsinki, Finland.

E-mail address: karri.silventoinen@helsinki.fi (K. Silventoinen).
} 
et al., 2018) and the incidence of metabolic diseases such as diabetes (Vazquez et al., 2007). It is also noteworthy that even with the wellknown tendency to underreport BMI (Connor Gorber et al., 2007), the correlation between self-reported and measured BMI is very high, allowing for the correct rank order of participants (Korkeila et al., 1995). There are differences in the average body-fat levels in persons from different ethnic groups having the same BMI (Deurenberg et al., 2002), but the problems are less severe if different ethnicities are not pooled together or if this effect is taken into account statistically. Thus, in epidemiological studies estimating the health risks of obesity, BMI offers a cost-effective way to measure obesity at the population level and is still used in most current epidemiological studies as the obesity indicator.

During the last decades, the global mean BMI level has dramatically increased in both children and adults, and there are large differences between geographic regions even in high income countries, with the highest BMI level in North America and lowest in East Asia (NCD Risk Factor Collaboration, 2017). This suggests that obesity is sensitive to changes in the macro-environment. There has been a lot of discussion on which specific factors could be behind of obesogenic environments, but they are still poorly understood (Kirk et al., 2009). However, in particular, increased availability of highly processed fast food (Zobel et al., 2016) and increased consumption of high-energy soft drinks are suggested to have importantly contributed to the obesity epidemic (Basu et al., 2013). There are convincing epidemiological data showing that soft drink consumption is associated with higher BMI (GarduñoAlanís et al., 2019) and increased weight gain in both children and adults (Luger et al., 2017; Malik et al., 2013). Physiologically, the association between soft-drink consumption and increased energy intake is expected, since high-energy drinks have only a weak satiety response (Maersk et al., 2012).

In the context of this review focusing on the genetics of BMI, it is noteworthy that even when genetic factors importantly explain individual differences in BMI and other obesity indicators, environmental factors are probably the key factors behind the time trends and geographic differences in obesity. Thus, the interaction between genetic and environmental factors is important in understanding the reasons behind individual differences in obesity as well as the time trends and between-country differences in obesity. A classic example on the importance of the interplay between genes and the environment in the obesity epidemic is the Pima Indians living in Arizona. The obesity level and prevalence of metabolic diseases were very low within the tribe in the early $20^{\text {th }}$ century, but after the Second World War dramatic changes in their environment ruined their traditional way of life, leading to a Westernized diet and consequently a dramatic obesity epidemic within the tribe (Pratley, 1998). This suggests that the Pima Indians have a strong genetic predisposition to weight gain, but it is expressed only in the context of a Westernized diet and more generally the Westernized lifestyle. BMI also shares genetic variation with arterial stiffness (Tarnoki et al., 2013) and metabolic disorders (Silventoinen et al., 2017a), which can indicate pleiotropy but also causal associations between BMI and other metabolic traits. It is likely that environmental factors can modify this genetic covariance, as suggested by the current very high level of metabolic diseases in Pima Indians as compared to other ethnic groups in North America (Fagot-Campagna et al., 2000).

Physiologically, obesity is caused by a long-term imbalance between energy intake (eating) and energy consumption (physical activity). Physical activity can be important in weight control (Fogelholm and Kukkonen-Harjula, 2000), and different opportunities for organized sports in boys and girls can also contribute to sex differences in childhood obesity (Nogueira et al., 2019). Additionally, other factors than eating and physical activity have been suggested to contribute to the obesity epidemic (McAllister et al., 2009). For example, cigarette smoking can lead to reduced weight through increased energy expenditure or decreased appetite (Audrain-McGovern and Benowitz,
2011). Further, there is strong evidence that the gut microbiome is associated with BMI (Falony et al., 2016), but the background of this association is poorly understood and probably reflects complex and reciprocal pathways between the host and microbiota (Mörkl et al., 2017). However, studies on twins (Goodrich et al., 2014) and individuals with different degrees of genetic relatedness (Rothschild et al., 2018) have suggested that genetic factors have only a small effect on gut microbiota, and thus it probably does not importantly contribute to the genetic variation of BMI. Even when not the only factor affecting obesity, eating should be considered as the main cause behind the obesity epidemic because obesity is fundamentally caused by not modifying energy intake according to energy consumption. We present a hypothesis that obesity should be regarded as a neuro-behavioral disease having a strong genetic background mediated largely by eating behavior and being sensitive to the macro-environment and analyze how previous twin and molecular genetic research has supported this hypothesis.

\section{Principles and designs of genetic family studies}

Back when the human genome was not yet decoded, the family design offered the only possibility to estimate the role of genetic and environmental factors behind inter-individual variation. If only ordinary siblings are available, the role of genetic and shared environmental factors cannot be distinguished, but they are combined as familial factors. By using extended pedigrees, twins or adopted children, it is, however, possible to utilize the different genetic relatedness of relatives to decompose the genetic and environmental variations. The principles of genetic family studies were already presented by Ronald Fisher (1918), and after that especially the twin design has been extensively used to study a large number of traits (Polderman et al., 2015).

The adoption design offers the most straightforward way to separate genetic and environmental components since the correlation between adoptive children and biological parents can be taken as evidence on the role of genetic factors and the correlation of adoptive children with adoptive parents and adoptive siblings as evidence on the role of the family environment. However, the adoption design is problematic since it ignores a possible genetic correlation between adoptive children and parents (many adoptions are done within relatives) and an environmental correlation between biological parents (e.g., intrauterine conditions, early childhood environment and later contacts with biological parents). These issues have probably become more important nowadays when adoptions have increasingly been done at later ages and also since contact with biological parents is encouraged in many countries. However, a more fundamental issue related to the adoption design is that both adoptees and adopting parents are selected. An adoption is usually a consequence of severe social, economic or health problems in the biological family. On the other hand, adoptive parents are highly motivated and carefully selected, thus decreasing environmental variation between adoptive families.

The most commonly used approach to estimate genetic and environmental variation is to utilize the information of monozygotic and dizygotic twins. Monozygotic twins are virtuously identical at the genesequence level, whereas dizygotic twins share half of their genetic variation, as with ordinary siblings. If raised together, both type of twins are assumed to share the same amount of environmental variation, which can include the influence of the childhood home as well as, for example, common friends. This allows decomposing the trait variation into genetic variation, environmental variation shared by cotwins and environmental variation unique to each twin; in the simple twin models, the unique environmental variation also includes measurement error (Posthuma et al., 2003). When studying BMI or other traits changing over lifetime, a special advantage in studying twins is that they are always at the same age. Because of these major advantages, most of the information on the influence of genetic factors on 


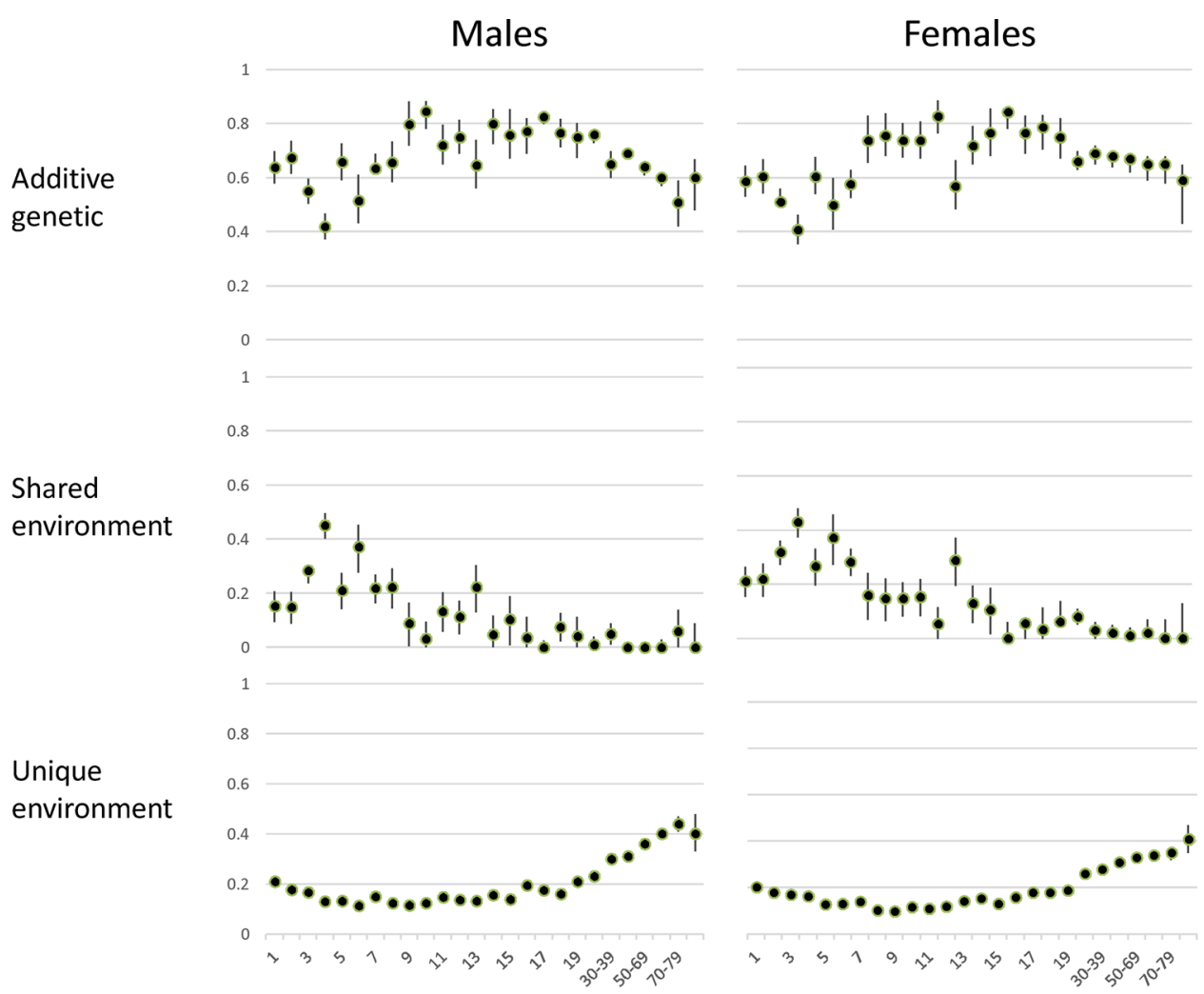

Fig. 1. The change of the proportions of BMI variation explained by additive genetic, shared environmental and unique environmental factors from infancy to old age in pooled twin data.

human characteristics before the genome-wide-association (GWA) studies became available were based on twin studies, and the twin design still offers a cost-effective shortcut to estimate the total genetic variation. Further, genetic twin studies allow for estimating environmental variation shared and unshared by co-twins and thus provides an understanding of the role of environmental factors, which is not possible in GWA studies.

\section{Family studies on obesity}

\subsection{Extended pedigree studies}

The logic of extended pedigree studies is to collect information on relatives having different genetic and environmental relatedness, thus allowing for estimation of genetic and environmental variation. However, in some cases even just collecting information on nuclear families is enough if the interest is only to take into account the total familial effect combining genetic factors and shared environment (Bogl et al., 2019). The history of family studies on BMI goes back to the early $20^{\text {th }}$ century when it was first shown that obesity clusters in families, indicating the importance of genetic factors (Davenport, 1923). After this initial study, family studies on BMI accumulated and in 1966 a review on family studies on obesity indicators was able to conclude that genetic factors importantly explain individual differences in obesity (Seltzer and Mayer, 1966). A review published in 2012 identified 27 heritability estimates of BMI based on family studies, excluding twin studies (Elks et al., 2012).

Although family studies show the importance of genetic factors well, it is noteworthy that heritability estimates based on the extended pedigree design are systematically lower than when based on the twin design (Elks et al., 2012). A likely explanation is that it is very difficult to measure non-twin siblings and other relatives at exactly the same age. Since different sets of genes affect body size and composition at different ages, the genetic correlation is less than 1 even for the same individual (see chapter 3.2). Thus, the underestimation of heritability is expected. However, there may also be other sources of variation leading to the lower heritability estimates in family studies as compared to twin studies. In a rare example of a family study having measured BMI at the same age (7 years of age) in parents and their offspring, the correlations were 0.36 or less (Ajslev et al., 2014). This is considerably lower than found for dizygotic twins at that age (Silventoinen et al., 2016b). This probably reflects the influence of environmental factors, but these environmental influences may be reinforced because of gene-environment interactions.

Although already used for nearly a century, the extended pedigree design is still utilized to estimate the effect of genetic factors on BMI. This approach is useful when studying populations where twin data or large GWA studies are not available, such as the Spanish Roma people (Poveda et al., 2012) or the Omani Arabs (Bayoumi et al., 2007). Additionally, increasing the possibilities to link pedigree information with medical records allows for collecting very large datasets with modest costs, allowing not only the estimation of the heritability of BMI and other obesity indicators but also how much they share a genetic background with other traits (Polubriaginof et al., 2018).

\subsection{Genetic twin studies}

Even though Francis Galton (1874) was already aware that there are two types of twins and speculated that they could be utilized to obtain information on the influence of genetic factors, the first twin study on the heritability of an obesity indicator (skinfold thickness) was done relatively late as compared to the long history of extended pedigree studies (Brook et al., 1975). Some years later, a relatively large twin study estimated the heritability of 0.77 for adult BMI (Stunkard et al., 1986a), which corresponds well to the later estimates in twin studies (Silventoinen et al., 2017b). After these first studies, a large number of twin studies estimating the heritability of BMI have been published. A meta-analysis published in 2012 identified 88 independent heritability 
estimates based on twin studies (Elks et al., 2012). Another meta-analysis published in 2010 and focusing only on the heritability of BMI in childhood in narrow age groups identified 9 twin studies (Silventoinen et al., 2010b).

Together these two meta-analyses found clear evidence that the heritability of BMI changes over the life course. More evidence on the changing heritability of BMI from infancy to adulthood was found in an individual-level pooled analyses of 24,000 twin children representing 4 countries (Dubois et al., 2012).

Fig. 1 summarizes the change of the genetic architecture of BMI from infancy to old age in a large pooled twin dataset of around 500 000 twins (Silventoinen et al., 2016b, 2017b). The genetic factors explained a slightly more than $60 \%$ of individual differences in BMI at $1-2$ years of age, but this proportion decreased to $40 \%$ at 4 years of age. The decline of the proportion of genetic factors is because environmental factors shared by co-twins become more important. After 4 years of age, the role of shared environmental factors started to decline and it largely disappeared at 13 years of age; at the same time, the importance of genetic factors increased, and their influence was strongest in early adulthood when they explained around $80 \%$ of BMI variation. From early adulthood to old age, the importance of genetic factors started to decline again, but this decline was because of the increasing importance of environmental factors unique to each twin. At $70-79$ years of age, genetic factors explained around $60 \%$ of individual differences in BMI.

This pattern of heritability can be interpreted to reflect the different opportunities to make individual choices at different life phases. In infancy, the caregiver mainly reacts to the crying of the baby and thus the baby can regulate energy intake well. In early childhood, parents can control the eating of their offspring more, seen as the increasing effect of shared environmental factors. However, during late childhood and adolescence, children become more independent from their parents. This is seen as the decreasing influence of shared environmental factors and the increasing influence of genetic factors when children can more freely select food based on their own preferences, having a partly genetic background. The influence of genetic factors is highest in early adulthood. After that, the proportion of genetic factors starts to decline again until old age when unique environmental factors become more important. This may reflect the long lasting influence of new environmental factors, such as the spouse, on BMI.

As seen in Fig. 1, the proportions of genetic and environmental variation are very similar in males and females. The twin design, however, also allows for analyzing whether there are sex-specific genetic factors affecting BMI. Fig. 2 summarizes the results of the change of genetic correlation within opposite-sex twins from infancy to old age (Silventoinen et al., 2016b, 2017b). Since the genetic correlation of same-sex dizygotic twins is always 0.5 , the lower correlations indicate that there are different genetic factors affecting BMI in males and females. The role of sex-specific genetic factors was already seen in early childhood. This result is interesting since the pre-puberty body composition is very similar in boys and girls (Malina et al., 2004). The influence of sex-specific genetic factors increased during puberty and then continuously increased over adulthood, as seen in decreasing genetic correlations for opposite-sex dizygotic twins. Since it is known that somewhat different genetic factors affect fat and muscle mass (Hasselbalch et al., 2008a), it is very likely that this result indicates the differences in body composition between males and females emerging during puberty. The increasing influence of these sex-specific genetic factors during adulthood is expected when differences in the hormonal levels between men and premenopausal women increasingly modify the expression of genes affecting BMI.

Longitudinal twin studies can also provide information on how genetic and environmental factors explain the continuity of BMI over the human life course. It is well known that childhood overweight is the most important risk factor for adult obesity (Baird et al., 2005). The only twin study having a full series of measures of BMI from 1 to 18 years of age is based on Swedish boys (Silventoinen et al., 2007b). This study shows that a moderate genetic correlation was already found with BMI at 1 and 18 years of age, but the correlation increased after 4 years of age and was 0.61 with BMI at 5 and 18 years of age. Since genetic variance also increases after that age (Silventoinen et al., 2016b), the result suggests that after early childhood new genetic variation in BMI emerges. There are also twin studies based on datasets from Australia (Cornes et al., 2007), Finland (Ortega-Alonso et al., 2012), Japan (Silventoinen et al., 2010a), the Netherlands (Silventoinen et al., 2007a) and the UK (Haworth et al., 2008) having incomplete series of BMI measures over childhood. Together, these studies confirm that there is strong genetic continuity of BMI over childhood. Thus, overweight in childhood should be regarded as a clear indicator of genetic susceptibility for obesity in adulthood.

Longitudinal twin studies have also been conducted on weight gain over adulthood. Heritability estimates from 0.57 to 0.70 for weight change in adulthood have been reported in US (Austin et al., 1997; Fabsitz et al., 1994) and Finnish studies (Hjelmborg et al., 2008; Ortaga-Alomso et al., 2009), but lower heritability estimates have also been reported (Hunt et al., 2002; Rice et al., 1999). Interestingly, a Finnish study reported only a weak genetic correlation between baseline BMI and weight change trajectory (Hjelmborg et al., 2008), but

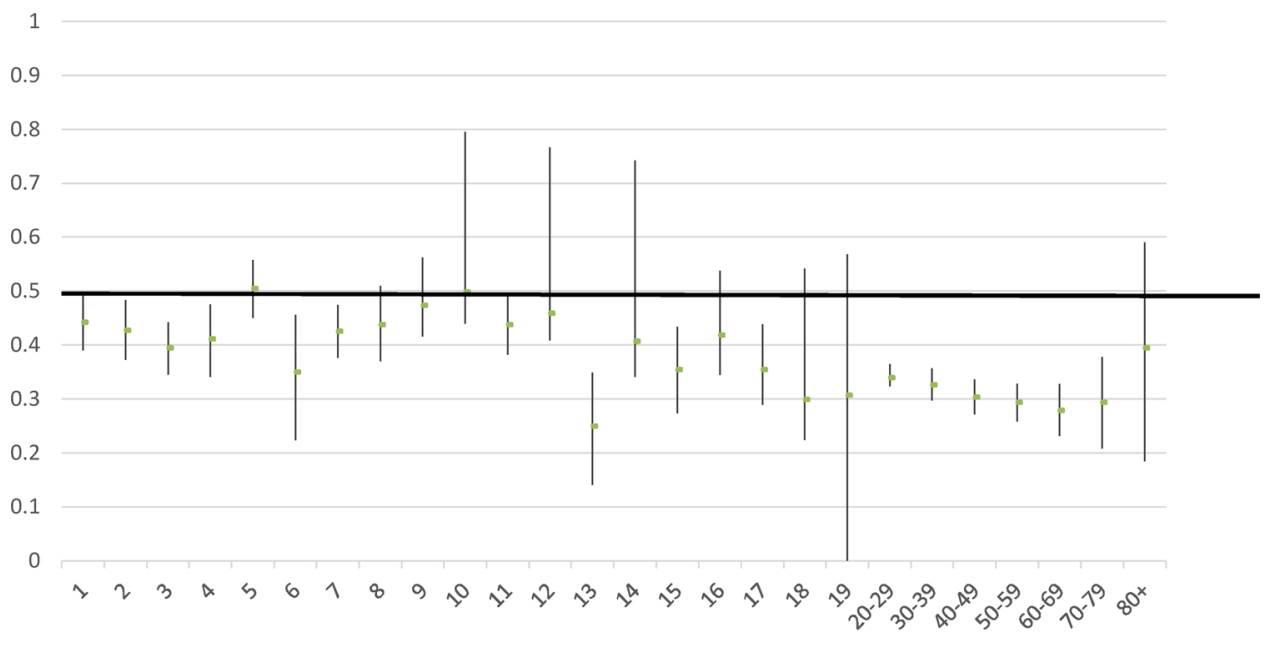

Age

Fig. 2. Additive genetic correlations for BMI within opposite-sex DZ pairs from infancy to old age in pooled twin data. 
there are also studies reporting moderate genetic correlations (Franz et al., 2007; Ortaga-Alomso et al., 2009). These studies suggesting that the genetic correlations are from weak to moderate may indicate that different genes affect BMI in early adulthood and weight gain after that. Since it is known that weight gain over adulthood is mainly caused by the accumulation of fat mass (Tchernof and Després, 2013), this conclusion may not be surprising. Thus, the same candidate genes affecting BMI in early adulthood may not necessarily predict further weight gain.

\subsection{Adoption studies}

In addition to the extended pedigree and twin designs, the adoption design offers the third possibility to analyze how genetic and environmental factors affect obesity. The first study analyzing BMI using this design found modest correlations ( 0.24 or less) with both adoptive and biological parents in a UK dataset (Withers, 1964). After this initial study, adoption studies have been conducted in Denmark (Sørensen et al., 1992; Stunkard et al., 1986b), the US (Cardon et al., 1995; Hartz et al., 1977) and Canada (Biron et al., 1977). Most of the participants in these studies include children, and none of them has been conducted recently. This is understandable since it is difficult to collect information on adopted children when they are already adults and currently domestic adoptions have become increasingly rare and selective.

The main conclusion of these adoption studies is that the BMI of children is correlated with the BMI of adoptive and biological parents and siblings; the correlations in these adoption studies have been previously summarized (Silventoinen et al., 2010b). However, the correlations with both adoptive and biological parents are low probably partly reflecting different sets of genes affecting BMI in childhood and adulthood. Thus, adoption studies can tell us little on the heritability of BMI. However, the value of adoption studies is that they give more direct evidence that also the rearing environment, measured as part of the shared environment in twin studies, also has an effect on BMI in childhood.

Even as domestic adoptions have become rare, international adoptions still offer an interesting opportunity to analyze the role of genetic factors behind the obesity levels in different ethnicities. A Swedish study of male native-born Swedish and international adoptees found that in young adulthood BMI was higher in adoptees from Latin America and lower in adoptees from the Indian subcontinent, East Asia, Ethiopia and Iran than in native-born Swedish (Johansson-Kark et al., 2002). Interestingly, these ethnic differences parallel current global differences in BMI (NCD Risk Factor Collaboration, 2017). Thus, it is possible that the global pattern of BMI is not totally caused by cultural factors but may also reflect genetic differences.

\subsection{Factors modifying heritability estimates}

According to the basic principle of twin and family studies, heritability estimates are not constant but may vary between different environments. The modification effects of environmental factors on the genetic variation of BMI are interesting because they can indicate gene-environment interactions, i.e., that specific environmental factors can suppress or reinforce the effect of genes predisposing to obesity (Boomsma and Martin, 2002).

There is good evidence that the genetic variance of BMI increases along with increasing mean BMI. Studies including Swedish male twins and full brothers measured in early adulthood (Rokholm et al., 2011b) and Danish middle-age male and female twins (Rokholm et al., 2011a) found increasing genetic variance in these countries during the obesity epidemic. These results were confirmed in a large international study where the genetic variance of adult BMI increased from the 1960s to 2010s along with increasing mean BMI (Silventoinen et al., 2017b). Since unique environmental variation also increased, only minor and unsystematic differences were found in the heritability of BMI. It is noteworthy that similar secular change in the genetic and environmental variances in height were not found, even though mean height also increased during the $20^{\text {th }}$ century (Jelenkovic et al., 2016b). This shows that there is no link between mean and variance in the anthropometric traits in general, and this result is specific to BMI.

Another possibility to analyze how the macro-environment modifies the heritability of BMI is to compare countries with different obesity prevalence, indicating differences in obesogenic environments. The first international effort using twins included data on adult BMI from eight countries all representing Caucasian populations. This study found differences in the genetic and environmental variances but did not find any systematic pattern (Schousboe et al., 2003). Another international study pooling eight cohorts of adolescent twins found higher genetic variation in Western countries as compared to East Asian countries; however, since environmental variation was also higher in Western populations, only minor differences were found in the heritability estimates of BMI (Hur et al., 2008). These initial results were confirmed in two large international studies where countries were classified into three cultural-geographic regions according to the population-level BMI. According to these studies, both genetic and environmental variation in BMI in children and adults were highest in North America and Australia representing a high level of obesogenic environments, followed by Europe, representing an intermediate level of obesogenic environments, and were lowest in East Asia, representing a low level of obesogenic environments (Silventoinen et al., 2016b, 2017b). According to the results of secular trends, in height no similar geographic differences were found in the genetic or environmental variances despite differences in mean stature, showing that this is a specific result for BMI (Jelenkovic et al., 2016a, 2016b).

In addition to the macro-environment, the social micro-environment is also important to obesity. There is a lot of evidence showing that both childhood socio-economic environment (Gustafson and Rhodes, 2006) and one's own social position in adulthood (McLaren, 2007; Sobal and Stunkard, 1989) are inversely associated with BMI. A study based on two Danish cohorts of adoptees found that socio-economic status of both biological and adoptive parents were equally associated with the BMI of adopted children, suggesting that both genetic factors and the rearing environment affect this association (Fontaine et al., 2011). Intriguingly, the association between social position and body fatness is not limited to humans. For example, subordinate female rhesus monkeys had higher caloric consumption than dominant monkeys (Wilson et al., 2008), and starlings with a disadvantageous early life environment were fatter in adulthood and spent more effort for food gathering than those with more advantaged early life environments (Andrews et al., 2015). Even when it would be attractive to consider that these parallel results in different species would suggest deep neurophysiological pathways, it is noteworthy that the inverse association between social position and BMI may not be universal, even in industrialized societies. Most of the previous studies have been conducted in Caucasian populations following a Westernized diet, but there is evidence that in Japan a similar social gradient in mean BMI as found in Western countries does not exist (Silventoinen et al., 2013). Thus, this association could be specific only to societies following a Westernized lifestyle.

A Dutch twin study found that low parental education increases the genetic variation of BMI in children (Silventoinen et al., 2016a), and Danish (Johnson et al., 2011) and US twin studies (Dinescu et al., 2016) found that one's own low education is associated with increased genetic variance of adult BMI. The modification effect of parental education on the genetic and environmental variation of BMI from infancy to old age in three cultural-geographic regions was analyzed in a large database of twins (Silventoinen et al., 2019). This study confirmed that low parental education is associated with increased genetic and environmental variation at all ages. The parental modification effect on BMI variances started to increase after 4 years of age. Interestingly, parental education had the strongest effect on the mean and variance of BMI in North America and Australia. These effects were smaller in Europe and 
weakest, if existing at all, in East Asia. This suggests that obesogenic environments not only affect mean BMI at the population level but can also modify socio-economic differences in BMI by reinforcing or suppressing the effect of genetic factors affecting BMI.

\subsection{Experimental and discordant pair twin studies}

Twin design is useful not only since it allows for the estimation of genetic and environmental variation but also because the comparison of monozygotic co-twins allows for optimally taking into account the effect of genetic factors. Comparing monozygotic twins is so strong a design that sometimes only one pair is enough for a study, such as when analyzing the effect of weightlessness on human physiology by using measures of an astronaut during a space flight and simultaneous measures of his retired astronaut monozygotic twin brother (GarrettBakelman et al., 2019). These studies not focusing on the genetics of BMI are, however, outside of the scope of this review. On the other hand, we present a few examples to demonstrate the experimental and discordant pair twin designs when studying obesity. Early studies using this approach analyzed how overfeeding 6 monozygotic twin pairs for 22 days (Poehlman et al., 1986), 10 pairs for 100 days (Mauriège et al., 1992) and 12 pairs for 84 days (Bouchard et al., 1990) affected body weight and metabolism. These studies concluded that body weight, fat mass and the lipolysis of abdominal fat tissue reacted more similarly within than between pairs suggesting that there are genetic differences in the reaction to excess energy intake. A similar approach has later been used, for example, to analyze how an eight-week exposure to a low- or high-fat diet affects fat taste sensitivity (Costanzo et al., 2018). The study showed that increased fat intake decreased fat taste sensitivity, but the change was not more similar within than between twin pairs. This suggests that the association between nutrient fat content and fat taste sensitivity is not affected by genetic factors.

Comparing discordant twin pairs can provide evidence on causality that is difficult to show when studying unrelated individuals. For example, it has been well demonstrated in large epidemiological studies that low birthweight is associated with lower BMI later in life (Rasmussen and Johansson, 1998; Seidman et al., 1991). However, this association can also be because of genetic factors affecting body size during fetal life or through the maternal body size because of the genetic correlation between mother and offspring. In a large international twin study, it was found that within monozygotic pairs discordant for birthweight, a lighter co-twin at birth had lower BMI from infancy until adulthood as compared to a heavier co-twin (Jelenkovic et al., 2017). This shows that the intrauterine conditions can have a long-lasting effect on later BMI even when the role of genetic factors has been taken into account.

The same design has been used to analyze the associations of smoking and the gut microbiome with BMI. Epidemiological studies have suggested that smoking is associated with lower BMI (AudrainMcGovern and Benowitz, 2011). A large international twin study found that a similar association can also been found in smoking discordant pairs when a smoking co-twin has, on average, lower BMI than a never smoking co-twin (Piirtola et al., 2018). This provides further evidence that smoking is causally associated with reduced BMI. In a similar way, BMI discordant monozygotic twins were used to test a hypothesis that higher gut microbiome diversity is associated with lower BMI (Finnicum et al., 2018). The study was able to demonstrate this association when using twins as individuals, but in a within-pair analysis, the association was not statistically significant, possibly because of the small number of pairs and relatively small BMI within-pair difference. This reflects the general challenge of using BMI discordant monozygotic pairs: even though the design is powerful, BMI is so highly heritable that monozygotic pairs having sufficiently large BMI differences are rare. Thus, large datasets are needed to be able to identify a sufficient number of BMI discordant twin pairs.

Recently, epigenetic studies have created new uses for the discordant twin pair design. Comparison of epigenetic changes of monozygotic twins discordant for a trait is very informative because of the same gene sequence. Additionally, since gene-expression, affected by methylations and other factors, changes over aging, it is convenient that co-twins have always the same age. Epigenetic research is outside the scope of this review, but this approach has been successfully used to analyze, for example, the gene expression of fat tissue in twins discordant for BMI (Muniandy et al., 2017).

\section{Molecular genetic studies on obesity}

\subsection{Candidate genes and genetic linkage studies}

The first molecular genetic studies on obesity were based on the identification of candidate genes associated with clinically defined obesity (Dai et al., 2013). There is a number of monogenic syndromes of obesity following Mendelian inheritance (Kaur et al., 2017). These gene findings provided, however, only minimal information on the genetic background of common obesity.

When analyzing the normal variation of BMI and other obesity indicators, genetic linkage studies offered the earliest possibility to identify chromosomal regions related to common obesity. The genetic linkage analysis is based on the principle that close chromosomal regions are commonly inherited together, known as linkage disequilibrium. Based on this principle, it is possible, by using genetic markers, to calculate the association between genetic and phenotypic similarity over the human genome within siblings and other relatives, providing evidence on the importance of certain chromosomal regions on the phenotype (Pulst, 2012). For BMI, a number of genetic linkage studies were conducted, but they largely failed to produce replicable results in further studies (Wu et al., 2012).

To summarize, the early candidate gene and genetic linkage studies provided only minimally useful information on the genetic basis of common obesity. This is understandable since these methods are most feasible when finding rare genetic variants having large effect sizes, whereas the genetic variation of common obesity, as proved later, is caused by a large number of genetic variants having only small effect sizes.

\subsection{Genome-wide-association studies}

The breakthrough in the study of the genetics of common obesity, as well as other polygenetic traits, happened when the HapMap consortium made it possible to sufficiently capture the variation of haplotypes over the human genome (International HapMap Constortium, 2007). As compared to candidate gene and genetic linkage studies, GWA studies made it possible to observe the effect of common genetic variants having only small effect sizes on the trait. As proposed earlier by Ronald Fisher (1918), this is the basic genetic mechanism of human anthropometric traits, including obesity traits: thus GWA studies have been very productive for understanding the genetic background of human obesity.

The first GWA studies on BMI in 2007 were able to find the locus in the FTO gene (Frayling et al., 2007; Scuteri et al., 2007), which has later proved to be the most important candidate gene of obesity; however, even this gene explains only $0.34 \%$ of BMI variation (Loos and Bouchard, 2008). After these first findings, the information based on GWA studies increased rapidly. A recent meta-analysis combining the results of GWA studies of European ancestry found 941 near-independent single nucleotide polymorphisms (SNPs) for BMI which, however, explained only $6.0 \%$ of BMI variation in an independent sample (Yengo et al., 2018). Since the heritability of adult BMI calculated by using the twin design varies between $60 \%$ and $80 \%$ depending on age (Silventoinen et al., 2017b), these candidate genes explain only a fraction of the total genetic variation confirming the highly polygenic nature of BMI. When considering all genetic variation over 
the genome, the explained BMI variation is expectedly much larger. In a recent unpublished study using whole genome sequence data on participants of European ancestry, $40 \%$ of BMI variation was explained by genetic variation (Wainschtein et al., 2019). Even though this is a much larger proportion than in earlier GWA studies, it is still much lower compared to the heritability estimates of adult BMI (Silventoinen et al., 2017b). Interestingly, this same study was able to explain $79 \%$ of height variation by genetic variation, which is very close to the heritability estimates based on twin data (Jelenkovic et al., 2016b). This suggests that when compared to height, the genetics of BMI are more complex, for example, because of the presence of gene-environment interactions.

In addition to GWA studies on BMI in populations of European ancestry, GWA studies in other populations have also been conducted. Studies in several East Asian populations (Wen et al., 2014) and Japanese (Akiyama et al., 2017) as well as indigenous populations such as Samoans (Naka et al., 2017) and Greenland Inuits (Grarup et al., 2018), have revealed some differences in the genetic architecture of BMI as compared to the populations of European ancestry. However, it is still too early to argue how much genetic differences can explain between population differences in BMI. In a study of European populations, the population mean of the genetic risk score (GRS) of BMI did not correlate with the population mean BMI whereas a correlation was found when studying the GRS of height and mean stature (Robinson et al., 2015). This suggests that environmental factors can mask the effect of genetic factors on BMI when studying differences between populations.

Most of the present GWA studies on BMI have been conducted in adults, but there is also information on loci associated with BMI in children. The largest meta-analysis thus far on childhood BMI found that largely the same loci associated with adult BMI affected BMI in childhood (Felix et al., 2016). This result is in accordance with previous twin studies showing a considerable genetic correlation of BMI in childhood and adulthood (chapter 3.2). However, the role of genetic variants may not be similar over childhood. There is evidence based on earlier genetic studies that the FTO gene and other obesity-related candidate genes have a stronger effect on BMI after 6 years of age (Elks et al., 2010; Rzehak et al., 2010; Sovio et al., 2011; Warrington et al., 2015). These results parallel with the evidence based on twin data finding that the genetic variation starts to increase after 4 years of age (Silventoinen et al., 2016b). Thus after early childhood, new genetic variation affecting BMI seems to emerge, which can explain well also the increasing genetic correlation with adult BMI after 4 years of age found in twin studies (chapter 3.2).

GWA studies have also been conducted on other obesity-related phenotypes. A GWA study of body fat percentage found overlap between SNPs previously found to be associated with BMI; however, four novel SNPs having genome-wide significance were also identified and the effect sizes of overlapping SNPs were different on body fat percentage and BMI (Lu et al., 2016). Additionally, a large GWA study on waist-to-hip ratio (WHR) adjusted for BMI identified several novel SNPs (Justice et al., 2019). These results suggest that even when there are a set of genes affecting general body fatness, there are separate genes regulating fat distribution.

\subsection{Mechanisms of genes associated with obesity}

GWA studies have produced evidence on the mechanisms of how genes are associated with obesity. This area is, however, complex and still poorly understood. The slowness in the understanding of these biological mechanisms is expected since the neurological and other physiological systems behind the maintenance of energy balance in humans are very complex (Lenard and Berthoud, 2008). However, this complexity can go down to the molecular genetic level. There is evidence that part of the association between the FTO gene and obesity goes through other genes (Claussnitzer et al., 2015). This underlines how difficult it is to confirm pathways from genes to phenotypes.
Previous large-scale GWA studies of BMI have found that the expression of SNPs associated with higher BMI are enriched in the brain especially in the hypothalamus, pituitary gland, hippocampus and limbic system (Locke et al., 2015; Turcot et al., 2018). These brain areas have an important role in appetite regulation, learning, cognition, emotion and memory (Lenard and Berthoud, 2008). These results are supported by findings that the orbitofrontal cortex gray matter volume mediated the association between the GRS of obesity and BMI (Opel et al., 2017). However, a similar negative association between the gray matter volume and BMI has also been found between monozygotic cotwins discordant for BMI (Weise et al., 2019). Thus, there is strong evidence for the role of behavioral factors - especially eating behavior behind the mechanisms between genes and BMI, but the reverse causality from BMI to behavior through the brain anatomy can also contribute to this association, possibly even reinforcing the effect of genes. On the other hand, SNPs associated with WHR adjusted for BMI seem to be especially related to lipid metabolism and adipose tissue regulation, also showing considerable differences in the effect sizes between males and females (Justice et al., 2019). This suggests that when the genetic factors of general adiposity affect through behavioral factors, genes regulating fat distribution influence through other mechanisms. These sex-specific differences in the genetic influences on fat distribution can also explain well the sex-specific genetic effect on BMI increasing during puberty and over adulthood, when the sexual dimorphism of fat distribution increases (see chapter 3.2).

\section{Genetics of eating behavior}

When considering the maintenance of energy balance, it seems obvious that the intake of macro-nutrients play the key role. This association is well demonstrated in anorexia nervosa in which severe restriction of eating leads to potentially life-threatening underweight. Other clinically defined eating disorders include bulimia nervosa, which does not necessarily lead to under- or overweight, and binge eating disorder, leading to severe overweight in many cases. All eating disorders are much more common in females than in males, but in binge eating disorder, the sex difference is smaller than in anorexia nervosa and bulimia nervosa (Raevuori et al., 2014). Previous twin and family studies have shown that genetic factors contribute to the liability of all eating disorders, with estimates from moderate to high heritability in different studies. Part of the genetic variation is also shared by anorexia nervosa and bulimia nervosa, suggesting that they partly share the same neurobiological background (Thornton et al., 2011). Previous twin studies have been underpowered to detect sex differences in the heritability of eating disorders, but there is some suggestive evidence that somewhat different sets of genes affect eating disorders in males and females (Culbert et al., 2011). GWA studies have been conducted for anorexia nervosa, whereas little is known on the candidate genes of bulimia nervosa and binge eating disorder (Himmerich et al., 2019). The latest GWA study on anorexia nervosa identified 8 significant loci, but they increased the risk of anorexia nervosa only slightly having odds ratios of 1.17 or less, thus demonstrating the highly polygenetic nature of eating disorders (Watson et al., 2019). Even though at the individual level eating disorders cause a lot of suffering and anorexia nervosa especially can be life-threatening, they are relatively rare disorders, having a prevalence of $1-4 \%$ in females and much lower prevalence (less than $1 \%$ ) in males based on European studies (KeskiRahkonen and Mustelin, 2016). Thus, they affect mean BMI and obesity prevalence only a small amount at the population level.

Given the evidence on the strong effect of anorexia nervosa on underweight and binge eating disorder on overweight, it may be surprising that the evidence of the importance of energy intake behind the global increase in mean BMI is largely indirect. A strong correlation has been detected between the changes of macronutrient consumption and BMI over time between countries, supporting the importance of increased food consumption behind the obesity epidemic (Silventoinen 
Table 1

Twin studies examining the genetic and environmental influences on macro-nutrient intake and eating patterns.

\begin{tabular}{|c|c|c|}
\hline Study & Participants & Measurement instrument \\
\hline $\begin{array}{l}\text { Pimpin et al. } \\
\qquad \text { (2013) }\end{array}$ & $\begin{array}{l}1216 \text { UK twin pairs measured at the mean age } \\
\text { of } 21 \text { months (range 17.3-34.2 months) }\end{array}$ & $\begin{array}{l}\text { Food diaries recorded by parents or caretakers over } \\
3 \text { days ( } 2 \text { weekdays and } 1 \text { weekend day) }\end{array}$ \\
\hline Li et al. $(2016)^{1}$ & $\begin{array}{l}622 \text { Chinese (Jiaxing, Zhejiang province) } \\
\text { measured at } 7-15 \text { years of age }\end{array}$ & $\begin{array}{l}\text { A } 145 \text {-item self-administered food frequency } \\
\text { questionnaire on food intake during the previous } 12 \\
\text { months }\end{array}$ \\
\hline
\end{tabular}

Summary

Total energy intake: $\mathrm{a}^{2}=0.11(0.08,0.15) ; \mathrm{c}^{2}=$ $0.80(0.77,0.83) ; \mathrm{e}^{2}=0.09(0.07,0.10) ; \%$ of energy from protein $\mathrm{a}^{2}=0.08(0.06,0.10) ; \mathrm{c}^{2}=$ $0.87(0.85,0.89) ; \mathrm{e}^{2}=0.05(0.04,0.06) ; \%$ of energy from carbohydrate $\mathrm{a}^{2}=0.09(0.07,0.12) ; \mathrm{c}^{2}$ $=0.86(0.84,0.88) ; \mathrm{e}^{2}=0.05(0.04,0.06) ; \%$ of energy from fat $\mathrm{a}^{2}=0.10(0.07,0.12) ; \mathrm{c}^{2}=0.85$ $(0.83,0.88) ; \mathrm{e}^{2}=0.05(0.04,0.06)$

Total energy intake: $a^{2}=0.17(0.00,0.47) ; c^{2}=$ months $0.37(0.10,0.56) ; \mathrm{e}^{2}=0.46(0.39,0.55) ; \%$ of energy from protein $\mathrm{a}^{2}=0.00(0.00,0.13) ; \mathrm{c}^{2}=$ $0.40(0.26,0.47) ; \mathrm{e}^{2}=0.60(0.53,0.68) ; \%$ of energy from carbohydrate $\mathrm{a}^{2}=0.29(0.00,0.57) ; \mathrm{c}^{2}$ $=0.21(0.00,0.47) ; \mathrm{e}^{2}=0.50(0.42,0.58) ; \%$ of energy from fat $\mathrm{a}^{2}=0.52(0.23,0.63) ; \mathrm{c}^{2}=0.04$ $(0.00,0.31) ; \mathrm{e}^{2}=0.44(0.37,0.52)$

Dubois et al. $(2013)^{1}$

369 Canadian (Greater Montreal Area, Province of Quebec) twin pairs at the mean age of 9.0 years (range $8-10$ years)

A detailed recall of children and their parents on all food and drinks consumed during the past two days 600 Danish twin pairs at mean age of 38 years (range 18-67 years)

Hasselbalch et a $(2008 b)^{1}$
Beaver et al. (2012)

van den Bree et al. $(1999)^{1}$
US adolescents at mean age of 16 years (standard deviation of 1.75 years): 632 twins, 981 full siblings, 318 half siblings, 119 cousins and 267 unrelated individuals.

1648 US twin pairs 50 years of age or older.
In-depth questions and interviews on different areas of food consumption

Food frequency questionnaire asking consumption frequency and usual serving size. Factor analyses eating pattern and unhealthy eating pattern. were used to form two factors indicating a healthy

Total energy intake: $\mathrm{a}^{2}=0.35(0.01,0.47) ; \mathrm{c}^{2}=$ $0.00(0.00,0.24) ; \mathrm{e}^{2}=0.65(0.53,0.80) ; \%$ of energy from protein $\mathrm{a}^{2}=0.00(0.00,0.33) ; \mathrm{c}^{2}=$ $0.20(0.00,0.29) ; \mathrm{e}^{2}=0.80(0.66,0.91) ; \%$ of energy from carbohydrate $\mathrm{a}^{2}=0.19(0.00,0.42) ; \mathrm{c}^{2}$ $=0.09(0.00,0.30) ; \mathrm{e}^{2}=0.72(0.58,0.87) ; \%$ of energy from fat $\mathrm{a}^{2}=0.23(0.00,0.43) ; \mathrm{c}^{2}=0.07$ $(0.00,0.30) ; \mathrm{e}^{2}=0.70(0.57,0.86)$

Food frequency questionnaire of 247 food items and recipes asking the frequency of intakes per day, week or month

Total energy intake: $\mathrm{a}^{2}=0.32(0.17,0.42) ; \mathrm{c}^{2}=$ $0.00(0.00,0.00) ; \mathrm{e}^{2}=0.68(0.59,0.79) ; \%$ of energy from protein $\mathrm{a}^{2}=0.35(0.19,0.44) ; \mathrm{c}^{2}=$ $0.00(0.00,0.10) ; \mathrm{e}^{2}=0.65(0.56,0.76) ; \%$ of energy from carbohydrate $\mathrm{a}^{2}=0.42(0.25,0.51) ; \mathrm{c}^{2}$ $=0.00(0.00,0.12) ; \mathrm{e}^{2}=0.58(0.49,0.68) ; \%$ of energy from fat $\mathrm{a}^{2}=0.41(0.28,0.50) ; \mathrm{c}^{2}=0.00$ $(0.00,0.09) ; \mathrm{e}^{2}=0.59(0.50,0.69)$

Unhealthy eating habit scale: $\mathrm{a}^{2}=0.42, \mathrm{c}^{2}=0.00$, $\mathrm{e}^{2}=0.58$; healthy eating habit scale: $\mathrm{a}^{2}=0.51, \mathrm{c}^{2}$ $=0.00, \mathrm{e}^{2}=0.49$; fast food each week: $\mathrm{a}^{2}=0.33$, $\mathrm{c}^{2}=0.09, \mathrm{e}^{2}=0.58$

Healthy eating pattern: food use: $\mathrm{a}^{2}=0.23(0.02$, $0.43), c^{2}=0.16(0.03,0.29), \mathrm{e}^{2}=0.61(0.53$, $0.71)$; serving size: $\mathrm{a}^{2}=0.28(0.05,0.41), \mathrm{c}^{2}=$ $0.05(0.00,0.19), \mathrm{e}^{2}=0.67(0.59,0.77)$; consuming frequency: $\mathrm{a}^{2}=0.25(0.03,0.44), \mathrm{c}^{2}=$ $0.13(0.00,0.26), \mathrm{e}^{2}=0.62(0.54,0.72)$

Unhealthy eating pattern: food use $\mathrm{a}^{2}=0.53(0.35$, $0.59), c^{2}=0.00(0.00,0.12), e^{2}=0.47(0.41$, $0.55)$; serving size: $\mathrm{a}^{2}=0.44(0.23,0.53), \mathrm{c}^{2}=$ $0.02(0.00,0.15), \mathrm{e}^{2}=0.54(0.47,0.63)$; consuming frequency: $\mathrm{a}^{2}=0.41(0.27,0.48), \mathrm{c}^{2}=$ $0.00(0.00,0.09), \mathrm{e}^{2}=0.59(0.52,0.66)$ Healthy foods: $\mathrm{a}^{2}=0.51(0.43,0.56), \mathrm{c}^{2}=0.00$ $(0.00,0.05), \mathrm{e}^{2}=0.49(0.44,0.54) ;$ high-fat foods: $\mathrm{a}^{2}=0.42(0.27,0.47), \mathrm{c}^{2}=0.00(0.00,0.12), \mathrm{e}^{2}=$ $0.58(0.53,0.64)$; sweet foods: $\mathrm{a}^{2}=0.38(0.25$, $0.44), \mathrm{c}^{2}=0.00(0.00,0.10), \mathrm{e}^{2}=0.62(0.56$, $0.68)$; meat: $\mathrm{a}^{2}=0.31(0.15,0.45), \mathrm{c}^{2}=0.08$ $(0.00,0.20), \mathrm{e}^{2}=0.61(0.55,0.67)$

Fruit and vegetables: $\mathrm{a}^{2}=0.48(0.04,0.66), \mathrm{c}^{2}=$ $0.08(0.00,0.47), \mathrm{e}^{2}=0.44(0.34,0.56)$; high alcohol: $\mathrm{a}^{2}=0.42(0.00,0.57), \mathrm{c}^{2}=0.04(0.00$ $0.45), \mathrm{e}^{2}=0.54(0.43,0.68)$; traditional English diet: $\mathrm{a}^{2}=0.42(0.00,0.53), \mathrm{c}^{2}=0.00(0.00,0.39)$, $\mathrm{e}^{2}=0.58$ (0.47, 0.72); dieting: $\mathrm{a}^{2}=0.34(0.00$, $0.51), \mathrm{c}^{2}=0.05(0.00,0.43), \mathrm{e}^{2}=0.61(0.49$, $0.76)$; low meat: $\mathrm{a}^{2}=0.32(0.00,0.52), \mathrm{c}^{2}=0.08$ $(0.00,0.44), \mathrm{e}^{2}=0.60(0.48,0.75)$

\footnotetext{
${ }^{1}$ Relative variance component estimates and their $95 \%$ confidence intervals are re-calculated based on intra-class correlations. Abbreviations: $\mathrm{a}^{2}=$ the proportion of trait variation explained by additive genetic variation; $\mathrm{c}^{2}=$ the proportion of trait variation explained by environmental variation shared by co-twins; $\mathrm{e}^{2}=$ the proportion of trait variation explained by environmental variation unique to each twin individual.

et al., 2004). On the other hand, when using self-reported data, demonstrating the association between energy intake and BMI has been problematic (Lissner, 2002). One important contributing factor to this difficulty can be the underreporting of energy intake in obese persons, which was shown, for example, in a study of obesity discordant twins

using self-reported data, data reported by the co-twin and double-labeled water (Pietiläinen et al., 2010). This underreporting is also probably nutrient specific, and more underreporting in obese persons has been found in fat and carbohydrate, rather than in protein, consumption (Lissner, 2002).
} 


\subsection{Heritability of macronutrient intake}

Previous twin studies conducted in various populations have produced evidence on the role of genetic factors behind total energy and macro-nutrient (protein, carbohydrate and fat) intake. A summary of these studies is presented in Table 1 . Since in many studies only the results of best fitting models were presented, we re-calculated the estimates of additive genetic, shared environmental and unique environmental variance components using the intra-class correlations for monozygotic and dizygotic pairs by using the OpenMx package of $\mathrm{R}$ statistical software if they were reported in the study (Neale et al., 2016). Since the number of twins was low in many studies, only pooled results for males and females are presented because otherwise the confidence intervals would have been too wide to obtain meaningful results. Studies including young UK children at the average age of 21 months (Pimpin et al., 2013) and 7-15-years-old Chinese children (Li et al., 2016) found clear evidence that in addition to genetic factors, shared environmental factors also had an influence on total energy intake. On the other hand, a study of Canadian 9-year-old children (Dubois et al., 2013) and Danish adults (Hasselbalch et al., 2008b) found only evidence on the role of genetic but not shared environmental factors. The same applies to the proportions of energy from macro-nutrients. There is thus some suggestive evidence that the role of shared environmental factors on individual differences in macro-nutrient intake may diminish from childhood to adulthood, thus paralleling the results on genetic and environmental influences on BMI (chapter 3.2). However, more detailed studies on children and adults in the same populations are needed to shed more light on this hypothesis and preferably longitudinal studies would be conducted.

There are a number of twin studies which have identified different food consumption patterns, usually by explorative factor analyses, based on the consumption of different food items summarized in Table 1. In one study the participants were adolescents (Beaver et al., 2012) and in others adults (Keskitalo et al., 2008a; Teucher et al., 2007; van den Bree et al., 1999). The number of factors and their interpretation varied between the studies. However, the results were systematic, showing moderate heritability and only little evidence on the role of shared environmental factors. Thus, these results are consistent with the studies on the heritability of macro-nutrient intake, showing that shared environment has only a small effect on eating patterns after childhood.

Molecular genetic studies on macro-nutrient intake have also been conducted. A large GWA study found 12 suggestively significant loci affecting fat, protein or carbohydrate consumption; the expression of gene variants in both brain and adipose tissues was found (Merino et al., 2018). Previous studies of the role of well-known candidate genes of BMI, FTO and a genetic variant near MC4R, have produced mixed results: some studies have supported the higher food consumption in the carriers of risk alleles (Cecil et al., 2008; Qi et al., 2008; Wardle et al., 2009), other studies have found no association or have reported mixed results (Hasselbalch et al., 2010; Stutzmann et al., 2009; Tanofsky-Kraff et al., 2009). It is, however, noteworthy that various methods to measure macro-nutrient intake were used in these studies, which may partly explain the differences in results. A large meta-analysis of the effect of the FTO gene found that the risk allele was associated with higher dietary protein intake but, surprisingly, slightly lower carbohydrate intake and total energy consumption (Qi et al., 2015). The role of reporting bias explaining these conflicting results cannot be ruled out. Thus, the evidence of the effect of these wellknown candidate genes of BMI on macro-nutrient intake is still conflicted.

\subsection{Heritability of eating behavior traits}

Eating behavior traits influence energy intake through choices about when, where, what and how much to eat, including decisions about starting and stopping eating (French et al., 2012). Many studies have shown that these traits, such as eating in response to negative emotions (i.e., emotional eating) and other difficulties in the regulation of eating, predict weight gain, suggesting that they play a causal role in the development of obesity (Chaput et al., 2009; Koenders and van Strien, 2011; Konttinen et al., 2019; Savage et al., 2009). Twin and other genetic studies conducted in adults have often utilized different versions of the Three-Factor Eating Questionnaire (TFEQ) to assess these appetite traits. The original 51-item TFEQ contains separate scales for restrained eating, disinhibition and susceptibility to subjective feelings of hunger (Stunkard and Messick, 1985). Disinhibition refers to a tendency to overeat in response to a variety of food and eating stimuli (e.g., scent and sight of food, negative emotions, perceived stress, social events), while restrained eating reflects deliberate efforts to restrict food intake to control weight. The revised 18-item TFEQ-R18 assesses these traits with a slightly different configuration and contains scales for restrained eating, uncontrolled eating, and emotional eating (Karlsson et al., 2000).

In studies on adult Swedish male twins (Tholin et al., 2005) and adult Finnish and UK male and female twins (Keskitalo et al., 2008b), moderate heritability estimates were found for restrained eating (26-63 $\%$ ), uncontrolled eating (45-69\%) and emotional eating (9-60\%). No evidence on the effect of shared environmental factors was found. The latter study also found that phenotypic correlations between uncontrolled eating, emotional eating and BMI are largely due to common underlying genetic influences (Keskitalo et al., 2008b). In a family study of Amish adults, the heritability estimates of $28 \%, 40 \%$ and $23 \%$, respectively, were found (Steinle et al., 2002). These estimates are close to the estimates of twin studies, especially when considering that family studies can somewhat underestimate heritability (see chapter 3.1). This suggests that the genetics of eating behavior can be quite similar in different social contexts.

Molecular genetic studies have examined the associations between GRS for BMI and eating behavior traits. These studies are summarized in detail in chapter 6.2, and they provide evidence that SNPs associated with higher BMI affect these traits. More specifically, adults at higher genetic risk of obesity tend to be more prone to emotional eating, uncontrolled eating, subjective feelings of hunger, and disinhibition than those at lower genetic risk (Cornelis et al., 2014; de Lauzon-Guillain et al., 2017; Jacob et al., 2018; Konttinen et al., 2015).

\section{Interplay between eating behavior and the genetics of obesity}

There are two related lines of literature examining the interplay between eating behavior and the genetics of obesity. One line has concentrated on the gene-by-diet interactions in obesity, while another line has focused on eating behavior traits as a potential mediating mechanism through which genes influence body weight. It can be argued that both of these literatures tackle with the same wider question, whether eating behavior contributes to the genetic susceptibility to obesity.

\subsection{Gene-by-diet interactions in obesity}

It has been suggested that dietary intake can either reinforce or suppress the genetic predisposition to obesity depending on the quality of the diet, with unhealthy or excess intake having the former effect and healthy intake having the latter effect. In this literature, obesity-related individual SNPs as well as GRS have been used to measure genetic variation between individuals. Since simulations indicated that GRS has greater power than individual SNPs for detecting interactions with environmental factors (Marigorta and Gibson, 2014), emphasis will be given to studies using GRS for obesity (BMI or WHR) in this chapter.

The research on the gene-by-diet interactions in obesity has generally produced mixed evidence. Studies based on three US adult cohorts found that a higher intake of fried foods and sugar-sweetened 


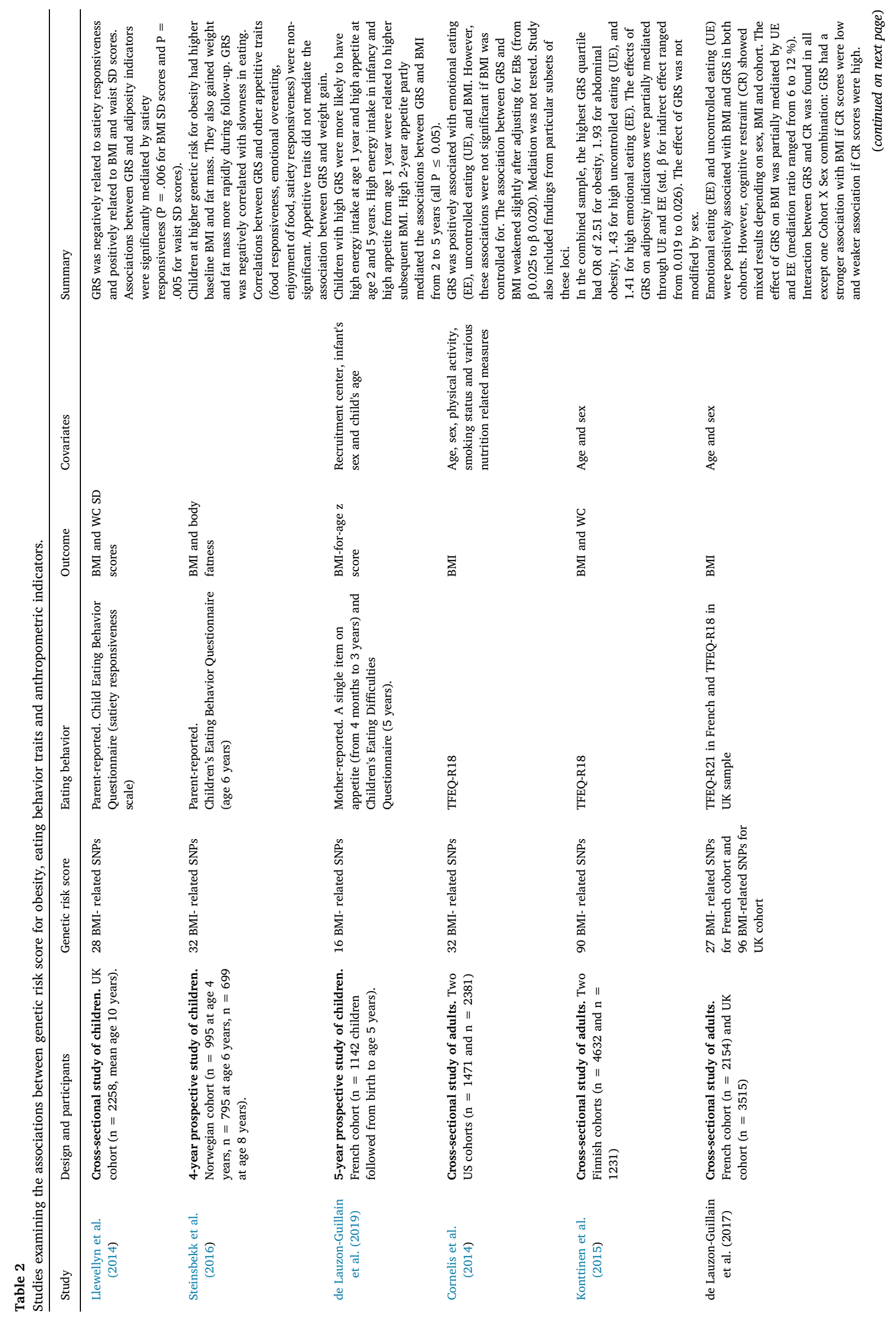


beverages enhanced the positive association between 32-loci GRS and BMI (Qi et al., 2012, 2014). These observations were not, however, supported by a large UK Biobank study in which the percentage of protein or fat in the diet, intake of fried foods or fizzy drinks, or consumption of a calorie-dense Western diet did not modify the genetic susceptibility to obesity (Tyrrell et al., 2017). Moreover, a study based on data from 18 cohorts of European ancestry investigated whether a composite score representing a healthy diet modified the effects of 32loci BMI-GRS and 14-loci WHR-GRS (Nettleton et al., 2015). This study surprisingly found that the effect of WHR-GRS on WHR adjusted for BMI was stronger in those with a healthier diet; no interactions were detected between the diet score and BMI-GRS.

As summarized previously, there are several methodological challenges associated with the gene-by-environment interaction studies, which are likely to play a role in explaining these inconsistent findings (Reddon et al., 2016). For instance, measuring dietary intake without biases is difficult (Lissner, 2002), and measurement error also generally attenuates the estimates of true effect sizes. Thus, more rigorous study designs better controlling for, for example, reporting bias would be necessary to analyze this issue further.

\subsection{Eating behavior traits as mediators in the genetics of obesity}

The literature testing the hypothesis that appetite-related eating behavior traits mediate the effect of genes on obesity has emerged rather recently. Mediation analysis provides one way to test this hypothesis in observational studies. In this particular mediation model, higher genetic predisposition to obesity (exposure) is expected to lead to increased appetite (mediator), which is expected to lead to higher body weight (outcome) over time. Thus, eating behavior traits are hypothesized to explain a part of the association between genes and obesity. Most studies in this area have used GRS for BMI to measure genetic variation between individuals. Table 2 summarizes findings from 7 studies conducted in adults or children.

Results from four cross-sectional studies analyzing various adult cohorts offer support for this mediation hypothesis (Cornelis et al., 2014; de Lauzon-Guillain et al., 2017; Jacob et al., 2018; Konttinen et al., 2015). More specifically, higher uncontrolled and emotional eating partly mediated the positive associations of GRS with BMI and waist circumference in two Finnish cohorts (Konttinen et al., 2015) and in French and UK cohorts (de Lauzon-Guillain et al., 2017). In a Canadian study, susceptibility to hunger as well as habitual and situational susceptibility to disinhibition acted as mediators (Jacob et al., 2018). Mediation was not formally tested in two US cohorts of older adults, but the effect of GRS on BMI weakened slightly after adjusting for restrained, uncontrolled and emotional eating (Cornelis et al., 2014).

Moreover, in a cross-sectional study of British 10-year-old twins, lower satiety responsiveness partly mediated the effects of GRS on higher BMI and waist circumference (Llewellyn et al., 2014). Results from a prospective French birth cohort showed that the positive associations between GRS and BMI from age 2 to 5 years were mediated by high appetite at age 2 years (de Lauzon-Guillain et al., 2019). However, there was no evidence for such a mediation effect in a Norwegian population-based prospective study utilizing weight gain between ages 4 and 8 years as an outcome (Steinsbekk et al., 2016). It is noteworthy, however, that measuring eating behavior traits and their mediation effect is more complicated in children than in adults due to several reasons. For example, younger children have limited control over their daily food choices and dependence on parent-reported (instead of selfreported) information may introduce extra bias.

Interestingly, recent findings from two adult studies could be interpreted to imply that restrained eating can be helpful in suppressing the genetic predisposition to obesity: the positive relationship of GRS with BMI (de Lauzon-Guillain et al., 2017) and weight gain from age 20 years to middle age (Konttinen et al., 2018) was somewhat stronger in 
participants with a low level of restrained eating than in those with a high level of restrained eating. It is possible that individuals recognize that they possess this predisposition (via its impact on increased appetite and body weight) and consequently engage in restrained eating as an attempt to counteract weight gain.

To summarize, an emerging body of literature suggests that the common risk variants for obesity can partly exert their effects through appetite-related eating behavior traits. However, limitations include that these findings are mainly based on cross-sectional data and especially results related to restrained eating need to be replicated. It should also be noted that the magnitude of both indirect (i.e. mediated) and direct associations have been small: for instance, in the Finnish study (Konttinen et al., 2015), the effect of BMI-GRS on emotional and uncontrolled eating was only around half of the size of the effect of this GRS on BMI. However, since these eating behavior traits depend on selfreport scales, they are inherently measured less reliably than anthropometric indicators, which may limit the size of the associations with genotype.

\section{Conclusions}

A century of genetic family studies and a decade of GWA studies have dramatically increased our understanding on the genetic architecture of common obesity, eating behavior and their mutual associations. However, this increasing knowledge has also clearly demonstrated the challenges, especially when trying to understand the mechanisms of how genes affect BMI and other obesity indicators.

BMI has been shown to be a highly heritable trait, but the heritability changes over the life course. The heritability estimates of BMI are lower in childhood and in old age as compared to early adulthood and middle-age. In childhood, the lower heritability is because of the influence of environmental factors shared by co-twins and in old-age because of environmental factors unique to each twin. The similar pattern of increasing influence of genetic factors and diminishing effect of the shared environment during late childhood and adolescence has been reported for many psychological traits, such as intelligence (Plomin and Deary, 2015), and probably reflects the changing dynamics of the interplay between genes and the environment. During adolescence, dependence on parents decreases, social networks widen, influence from peers become stronger and sensation-seeking increases (Ahmed et al., 2015; Kilford et al., 2016). This probably leads to the possibility to more freely create one's own environment, including the environment influencing BMI, which is partly affected by genetically influenced preferences. There is a lot of evidence for this so-called active gene-environment correlation for psychiatric traits (Jaffee and Price, 2007), and genetic factors have been found to influence life events, also demonstrating the dependence of genes and environment (Kendler and Baker, 2007). However, for BMI the direct evidence on gene-environment correlations is still suggestive. Studies on the heritability of macro-nutrient intake and eating patterns suggest that shared environmental factors have effect on eating behavior in childhood and adolescence, and this influence disappears until adulthood. Twin and molecular genetic studies have shown that after early childhood new genetic variance emerges. It is very possible that this genetic variance is related to eating behavior when children can more independently regulate their own eating, but direct evidence is still lacking. There is some evidence that eating behaviors can modify the genetic effects of obesity, but most of these studies are based on cross-sectional data and the results are somewhat mixed. Thus, more studies on how the interplay between genes and the environment modifies the genetic architecture of BMI during the formative years of childhood and adolescence are still needed.

The strong effect of genetic factors on BMI does not mean, however, that the family environment does not have effect on BMI. Adoption studies have clearly shown that the adoptive family also has an effect on BMI. A likely explanation for these results is that the family environment affects BMI by reinforcing the effect of genes affecting BMI. There is direct evidence on this based mainly on twin studies since both the micro-level environment (e.g., parental education) and the macro-level environment (measured as the level of obesity between countries and measurement years) affect the genetic variation of BMI. Thus, those children having a genetic susceptibility to obesity gain more weight in family environments or societies predisposing to obesity. These results underline the importance of community food environments, since they can suppress or reinforce the effects of genetic variants associated with obesity. There has been a lot of discussion on which specific community-level factors are behind the obesogenic environments, but there is no clear consensus (Kirk et al., 2009). The associations are also likely to be very complex, as found in a previous study demonstrating that the community food environment can modify how health counseling affects eating behavior (Lorts et al., 2019). There is a lack on studies whether the micro- and macro-environment can modify the genetic variation of macro-nutrient intake in a similar way as they affect the genetic variation of BMI. Thus, more research is needed to specify which community-level factors reinforce the genetic variation of BMI and analyze the role of eating behavior behind these associations.

GWA studies have clearly shown that BMI is a highly polygenic trait and thus confirms the basic principle of genetic family studies. The mechanisms of how genes affect BMI are still poorly understood, but the expression of the candidate genes of BMI in the brain tissue suggests that they affect BMI through behavioral factors. There is also evidence based on both twin and GWA studies that genetic factors affect macronutrient intake and appetite-related eating behavior traits. However, to date, there is only limited direct evidence on the overlap of genes affecting BMI and eating behavior which would suggest that the genes affect BMI through eating behavior. Some studies have shown this mediation effect, but they can explain only a fraction of the association between genetic factors and BMI. This area is, however, very challenging because of the well-known difficulties to measure dietary intake and reliance on self-report scales to assess eating behavior traits.

Some sex differences in the genetic architecture of obesity indicators were identified. In BMI the proportion of genetic variation was roughly similar in males and females from infancy to old age, but especially after puberty, somewhat different sets of genes started to affect BMI in males and females and this difference increased during adulthood. It is likely that this reflects differences in body composition since somewhat different sets of genes affect muscle and fat body tissues. Accordingly, the SNPs associated with WHR adjusted for BMI showed different effect sizes in males and females. Very little is still known on sex differences in the genetic architecture of eating behavior. Thus, it is too early to argue whether genetic factors affect obesity traits in males and females differently through eating behavior or whether the found differences reflect only endocrinological differences between the sexes.

At the beginning of this review we presented the hypothesis: Obesity is a neuro-behavioral disease having a strong genetic background mediated largely by eating behavior and being sensitive to the macroenvironment. There is strong evidence for this hypothesis based on previous genetic research, but the evidence that the genes affect especially through eating behavior is still emerging and mainly indirect at the moment. More rigorous prospective study designs controlling the well-known biases of measuring food intake would be necessary to prove this part of the hypothesis or to show that other behavioral mechanisms are also important when explaining the effect of genes on BMI.

\section{References}

Ahmed, S.P., Bittencourt-Hewitt, A., Sebastian, C.L., 2015. Neurocognitive bases of emotion regulation development in adolescence. Dev. Cogn. Neurosci. 15, 11-25.

Ajslev, T.A., Ängquist, L., Silventoinen, K., Baker, J.L., Sørensen, T.I.A., 2014. Trends in parent-child correlations of childhood body mass index during the development of 
the obesity epidemic. PLoS One 9, e109932.

Akiyama, M., Okada, Y., Kanai, M., Takahashi, A., Momozawa, Y., Ikeda, M., et al., 2017. Genome-wide association study identifies 112 new loci for body mass index in the Japanese population. Nat. Genet. 49, 1458-1467.

Andrews, C., Viviani, J., Egan, E., Bedford, T., Brilot, B., Nettle, D., Bateson, M., 2015. Early life adversity increases foraging and information gathering in European starlings, Sturnus vulgaris. Anim. Behav. 109, 123-132.

Audrain-McGovern, J., Benowitz, N.L., 2011. Cigarette smoking, nicotine, and body weight. Clin. Pharmacol. Ther. 90, 164-168.

Austin, M.A., Friedlander, Y., Newman, B., Edwards, K., Mayer-Davis, E.J., King, M.C., 1997. Genetic influences on changes in body mass index: a longitudinal analysis of women twins. Obes. Res. 5, 326-331.

Baird, J., Fisher, D., Lucas, P., Kleijnen, J., Roberts, H., Law, C., 2005. Being big or growing fast: systematic review of size and growth in infancy and later obesity. BMJ 331. https://doi.org/10.1136/bmj.38586.411273.EO.

Basu, S., McKee, M., Galea, G., Stuckler, D., 2013. Relationship of soft drink consumption to global overweight, obesity, and diabetes: a cross-national analysis of 75 countries. Am. J. Public Health 103, 2071-2077.

Bayoumi, R.A., Al-Yahyaee, S.A., Albarwani, S.A., Rizv, S.G., Al-Hadabi, S., Al-Ubaid, F.F., 2007. Heritability of determinants of the metabolic syndrome among healthy Arabs of the Oman family Study. Obesity 15, 551-556.

Beaver, K.M., Flores, T., Boutwell, B.B., Gibson, C.L., 2012. Genetic influences on adolescent eating habits. Health Educ. Behav. 39, 142-151.

Bell, J.A., Carslake, D., O’Keeffe, L.M., Frysz, M., Howe, L.D., Hamer, M., et al., 2018. Associations of body mass and fat indexes with cardiometabolic traits. J. Am. Coll. Cardiol. 72, 3142-3154.

Biron, P., Mongeau, J.G., Bertrand, D., 1977. Familial resemblance of body weight and weight/height in 374 homes with adopted children. J. Pediatr. 91, 555-558.

Bogl, L.H., Mehlig, K., Intemann, T., Masip, G., Keski-Rahkonen, A., Russo, P., et al., 2019. A within-sibling pair analysis of lifestyle behaviours and BMI z-score in the multicentre I.fAmily study. Nutr. Metab. Cardiovasc. Dis. 29, 580-589.

Boomsma, D.I., Martin, N.G., 2002. Gene-environment interactions. In: D’haenen, H., den Boer, J.A., Wilner, P. (Eds.), Biological Psychiatry. John Wiley \& Sons Ltd., New York, pp. 181-187.

Bouchard, C., Tremblay, A., Despres, J.P., Nadeau, A., Lupien, P.J., Theriault, G., et al., 1990. The response to long-term overfeeding in identical twins. N. Engl. J. Med. 322, 1477-1482.

Brook, C.G., Huntley, R.M., Slack, J., 1975. Influence of heredity and environment in determination of skinfold thickness in children. BMJ 2, 719-721.

Cardon, L.R., 1995. Genetic influence on body mass index in early childhood. In: Turner, J.R., Cardon, L.R. (Eds.), Behavior Genetic Approaches in Behavioral Medicine. Plenum Press, New York, pp. 133-143.

Cecil, J.E., Tavendale, R., Watt, P., Hetherington, M.M., Palmer, C.N., 2008. An obesityassociated FTO gene variant and increased energy intake in children. N. Engl. J. Med. 359, 2558-2566.

Chaput, J.P., Leblanc, C., Pérusse, L., Després, J.P., Bouchard, C., Tremblay, A., 2009. Risk factors for adult overweight and obesity in the Quebec Family Study: Have we been barking up the wrong tree? Obesity 17, 1964-1970.

Claussnitzer, M., Dankel, S.N., Kim, K.H., Quon, G., Meuleman, W., Haugen, C., et al., 2015. FTO obesity variant circuitry and adipocyte browning in humans. N. Engl. J. Med. 373, 895-907.

Connor Gorber, S., Tremblay, M., Moher, D., Gorber, B., 2007. A comparison of direct vs. self-report measures for assessing height, weight and body mass index: a systematic review. Obes. Rev. 8, 307-326.

Cornelis, M.C., Rimm, E.B., Curhan, G.C., Kraft, P., Hunter, D.J., Hu, F.B., van Dam, R.M., 2014. Obesity susceptibility loci and uncontrolled eating, emotional eating and cognitive restraint behaviors in men and women. Obesity 22, E135-E141.

Cornes, B.K., Zhu, G., Martin, N.G., 2007. Sex differences in genetic variation in weight: a longitudinal study of body mass index in adolescent twins. Behav. Genet. 37, 648-660.

Costanzo, A., Nowson, C., Orellana, L., Bolhuis, D., Duesing, K., Keast, R., 2018. Effect of dietary fat intake and genetics on fat taste sensitivity: a co-twin randomized controlled trial. Am. J. Clin. Nutr. 107, 683-694.

Culbert, K.M., Racine, S.E., Klump, K.L., 2011. The influence of gender and puberty on the heritability of disordered eating symptoms. In: Adan, R.A.H., Kaye, W.H. (Eds.), Behavioral Neurobiology of Eating Disorders. Springer, New York, pp. 177-185.

Dai, H.J., Wu, J.C., Tsai, R.T., Pan, W.H., Hsu, W.L., 2013. T-HOD: A Literature-Based Candidate Gene Database for Hypertension, Obesity and Diabetes. Database Oxford, bas061 2013.

Davenport, C.B., 1923. Body-build and Its Inheritance. Carnegie Institution of Washington, No. 329, Washington.

de Lauzon-Guillain, B., Clifton, E.A., Day, F.R., Clément, K., Brage, S., Forouhi, N.G., et al., 2017. Mediation and modification of genetic susceptibility to obesity by eating behaviors. Am. J. Clin. Nutr. 106, 996-1004.

de Lauzon-Guillain, B., Koudou, Y.A., Botton, J., Forhan, A., Carles, S., Pelloux, V., Clément, K., Ong, K.K., Charles, M.A., Heude, B., EDEN Mother-Child Cohort Study Group, 2019. Association between genetic obesity susceptibility and mother-reported eating behaviour in children up to 5 years. Pediatric Obesity 14 (e12496).

Deurenberg, P., Deurenberg-Yap, M., Guricci, S., 2002. Asians are different from Caucasians and from each other in their body mass index/body fat per cent relationship. Obes. Rev. 3, 141-146.

Dinescu, D., Horn, E.E., Duncan, G., Turkheimer, E., 2016. Socioeconomic modifiers of genetic and environmental influences on body mass index in adult twins. Health Psychol. 35, 157-166.

Dubois, L., Diasparra, M., Bédard, B., Kaprio, J., Fontaine-Bisson, B., Pérusse, D., et al., 2013. Gene-environment contributions to energy and macronutrient intakes in 9 year-old children: results from the Quebec Newborn Twin Study. Physiol. Behav. 119, 30-37.

Dubois, L., Ohm Kyvik, K., Girard, M., Tatone-Tokuda, F., Perusse, D., Hjelmborg, J., et al., 2012. Genetic and environmental contributions to weight, height, and BMI from birth to 19 years of age: an international study of over 12,000 twin pairs. PLoS One 7, e30153.

Elks, C.E., den Hoed, M., Zhao, J.H., Sharp, S.J., Wareham, N.J., Loos, R.J., Ong, K.K., 2012. Variability in the heritability of body mass index: a systematic review and meta-regression. Front. Endocrinol. (Lausanne) 3. https://doi.org/10.3389/fendo. 2012.00029.

Elks, C.E., Loos, R.J., Sharp, S.J., Langenberg, C., Ring, S.M., Timpson, N.J., et al., 2010. Genetic markers of adult obesity risk are associated with greater early infancy weight gain and growth. PLoS Med. 7, e1000284.

Fabsitz, R.R., Sholinsky, P., Carmelli, D., 1994. Genetic influences on adult weight gain and maximum body mass index in male twins. Am. J. Epidemiol. 140, 711-720.

Fagot-Campagna, A., Pettitt, D.J., Engelgau, M.M., Burrows, N.R., Geiss, L.S., Valdez, R., et al., 2000. Type 2 diabetes among North American children and adolescents: an epidemiologic review and a public health perspective. J. Pediatr. 136, 664-672.

Falony, G., Joossens, M., Vieira-Silva, S., Wang, J., Darzi, Y., Faust, K., et al., 2016. Population-level analysis of gut microbiome variation. Science 352, 560-564.

Felix, J.F., Bradfield, J.P., Monnereau, C., van der Valk, R.J., Stergiakouli, E., Chesi, A., et al., 2016. Genome-wide association analysis identifies three new susceptibility loci for childhood body mass index. Hum. Mol. Genet. 25, 389-403.

Finnicum, C.T., Doornweerd, S., Dolan, C.V., Luningham, J.M., Beck, J.J., Willemsen, G., et al., 2018. Metataxonomic analysis of individuals at BMI extremes and monozygotic twins discordant for BMI. Twin Res. Hum. Genet. 21, 203-213.

Fisher, R.A., 1918. The correlation between relatives on the supposition of Mendelian inheritance. Trans. R. Soc. Edinburgh 52, 399-433.

Flegal, K.M., Kit, B.K., Orpana, H., Graubard, B.I., 2013. Association of all-cause mortality with overweight and obesity using standard body mass index categories: a systematic review and meta-analysis. JAMA 309, 71-82.

Fogelholm, M., Kukkonen-Harjula, K., 2000. Does physical activity prevent weight gain-a systematic review. Obes. Rev. 1, 95-111.

Fontaine, K.R., Robertson, H.T., Holst, C., Desmond, R., Stunkard, A.J., Sørensen, T.I.A., Allison, D.B., 2011. Is socioeconomic status of the rearing environment causally related to obesity in the offspring. PLoS One 6, e27692.

Franz, C.E., Grant, M.D., Jacobson, K.C., Kremen, W.S., Eisen, S.A., Xian, H., et al., 2007. Genetics of body mass stability and risk for chronic disease: a 28-year longitudinal study. Twin Res. Hum. Genet. 10, 537-545.

Frayling, T.M., Timpson, N.J., Weedon, M.N., Zeggini, E., Freathy, R.M., Lindgren, C.M., et al., 2007. A common variant in the FTO gene is associated with body mass index and predisposes to childhood and adult obesity. Science 316, 889-894.

French, S.A., Epstein, L.H., Jeffery, R.W., Blundell, J.E., Wardle, J., 2012. Eating behavio dimensions: associations with energy intake and body weight. Appetite 59, 541-549.

Galton, G., 1874. The history of twins, as a criterion of the relative powers of nature and nurture. Fraser's Mag. 12, 566-576.

Garduño-Alanís, A., Malyutina, S., Pajak, A., Stepaniak, U., Kubinova, R., Denisova, D., et al., 2019. Association between soft drink, fruit juice consumption and obesity in Eastern Europe: cross-sectional and longitudinal analysis of the HAPIEE study. J. Hum. Nutr. Diet (E-pub ahead of print).

Garrett-Bakelman, F.E., Darshi, M., Green, S.J., Gur, R.C., Lin, L., Macias, B.R., et al., 2019. The NASA twins study: a multidimensional analysis of a year-long human spaceflight. Science 364, 144.

GBD 2015 Risk Factors Collaborators, 2016. Global, regional, and national comparative risk assessment of 79 behavioural, environmental and occupational, and metabolic risks or clusters of risks, 1990-2015: a systematic analysis for the Global Burden of Disease Study 2015. Lancet 388, 1659-1724.

Goodrich, J.K., Waters, J.L., Poole, A.C., Sutter, J.L., Koren, O., Blekhman, R., et al., 2014. Human genetics shape the gut microbiome. Cell 159, 789-799.

Grarup, N., Moltke, I., Andersen, M.K., Dalby, M., Vitting-Seerup, K., Kern, T., et al., 2018. Loss-of-function variants in ADCY3 increase risk of obesity and type 2 diabetes. Nat. Genet. 50, 172-174.

Griffiths, L.J., Parsons, T.J., Hill, A.J., 2010. Self-esteem and quality of life in obese children and adolescents: a systematic review. Int. J. Pediatr. Obes. 5, 282-304.

Gustafson, S.L., Rhodes, R.E., 2006. Parental correlates of physical activity in children and early adolescents. Sports Med. 36, 79-97.

Hartz, A., Giefer, E., Rimm, A.A., 1977. Relative importance of the effect of family environment and heredity on obesity. Ann. Hum. Genet. 41, 185-193.

Haslam, D., 2007. Obesity: a medical history. Obes. Rev. 8, S31-S36.

Hasselbalch, A.L., Angquist, L., Christiansen, L., Heitmann, B.L., Kyvik, K.O., Sørensen, T.I.A., 2010. A variant in the fat mass and obesity-associated gene (FTO) and variants near the melanocortin-4 receptor gene (MC4R) do not influence dietary intake. J. Nutr. 140, 831-834.

Hasselbalch, A.L., Benyamin, B., Visscher, P.M., Heitmann, B.L., Kyvik, K.O., Sørensen, T.I.A., 2008a. Common genetic components of obesity traits and serum leptin. Obesity 16, 2723-2729.

Hasselbalch, A.L., Heitmann, B.L., Kyvik, K.O., Sørensen, T.I.A., 2008b. Studies of twins indicate that genetics influence dietary intake. J. Nutr. 138, 2406-2412.

Haworth, C.M., Plomin, R., Carnell, S., Wardle, J., 2008. Childhood obesity: genetic and environmental overlap with normal-range BMI. Obesity 16, 1585-1590.

Himmerich, H., Bentley, J., Kan, C., Treasure, J., 2019. Genetic risk factors for eating disorders. Ther. Adv. Psychopharmacol. 12, 2045125318814734.

Hjelmborg, J.B., Fagnani, C., Silventoinen, K., McGue, M., Korkeila, M., Christensen, K. et al., 2008. Genetic influences on growth traits of BMI: a longitudinal study of adult twins. Obesity 16, 847-852.

Hu, F., 2008. Measurements of adiposity and body composition. In: Hu, F.B. (Ed.), Obesity 
Epidemiology. Oxford University Press, New York City, pp. 53-83.

Hunt, M.S., Katzmarzyk, P.T., Perusse, L., Rice, T., Rao, D.C., Bouchard, C., 2002. Familial resemblance of 7-year changes in body mass and adiposity. Obes. Res. 10, 507-517.

Hur, Y.M., Kaprio, J., Iacono, W.G., Boomsma, D.I., McGue, M., Silventoinen, K., et al., 2008. Genetic influences on the difference in variability of height, weight and body mass index between Caucasian and East Asian adolescent twins. Int. J. Obes. 32 1455-1467.

International HapMap Constortium, 2007. A second generation human haplotype map of over 3.1 million SNPs. Nature 449, 851-862.

Jacob, R., Drapeau, V., Tremblay, A., Provencher, V., Bouchard, C., Pérusse, L., 2018. The role of eating behavior traits in mediating genetic susceptibility to obesity. Am. J. Clin. Nutr. 108, 445-452.

Jaffee, S.R., Price, T.S., 2007. Gene-environment correlations: a review of the evidence and implications for prevention of mental illness. Mol. Psychiatry 12, 432-442.

Janssen, I., Katzmarzyk, P.T., Ross, R., 2004. Waist circumference and not body mass index explains obesity-related health risk. Am. J. Clin. Nutr. 79, 379-384.

Jelenkovic, A., Hur, Y.M., Sund, R., Yokoyama, Y., Siribaddana, S.H., Hotopf, M., et al., 2016b. Genetic and environmental influences on adult human height across birth cohorts from 1886 to 1994. Elife, e20320.

Jelenkovic, A., Sund, R., Hur, Y.M., Yokoyama, Y., Hjelmborg, J., Möller, S., et al., 2016a. Genetic and environmental influences on height from infancy to early adulthood: an individual-based pooled analysis of 45 twin cohorts. Sci. Rep. 6, 28496.

Jelenkovic, A., Yokoyama, Y., Sund, R., Pietiläinen, K.H., Hur, Y.M., Willemsen, G., et al., 2017. Association between birthweight and later body mass index: an individualbased pooled analysis of 27 twin cohorts participating in the CODATwins project. Int. J. Epidemiol. 46, 1488-1498.

Johansson-Kark, M., Rasmussen, F., Hjern, A., 2002. Overweight among international adoptees in Sweden: a population-based study. Acta Paediatr. 91, 827-832.

Johnson, W., Kyvik, K.O., Skytthe, A., Deary, I.J., Sørensen, T.I., 2011. Education modifies genetic and environmental influences on BMI. PLoS One 6, e16290.

Joint Committee on the Medico-Acturial Mortality Investigation, 1995. Classics in obesity: medico-acturial mortality investigation. orig. 1912. Obes. Res. 3, 100-106.

Justice, A.E., Karaderi, T., Highland, H.M., Young, K.L., Graff, M., Lu, Y., et al., 2019. Protein-coding variants implicate novel genes related to lipid homeostasis contributing to body-fat distribution. Nat. Genet. 51, 452-469.

Karlsson, J., Persson, L.O., Sjöström, L., Sullivan, M., 2000. Psychometric properties and factor structure of the three-factor eating questionnaire (TFEQ) in obese men and women: Results from the Swedish Obese Subjects (SOS) Study. Int. J. Obes. 24, 1715-1725.

Kaur, Y., de Souza, R.J., Gibson, W.T., Meyre, D., 2017. A systematic review of genetic syndromes with obesity. Obes. Rev. 18, 603-634.

Kendler, K.S., Baker, J.H., 2007. Genetic influences on measures of the environment: a systematic review. Psychol. Med. 37, 615-626.

Keski-Rahkonen, A., Mustelin, L., 2016. Epidemiology of eating disorders in Europe: prevalence, incidence, comorbidity, course, consequences, and risk factors. Curr. Opin. Psychiatry 29, 340-345.

Keskitalo, K., Silventoinen, K., Tuorila, H., Perola, M., Pietiläinen, K.H., Rissanen, A., Kaprio, J., 2008a. Genetic and environmental contributions to food use patterns of young adult twins. Physiol. Behav. 93, 235-242.

Keskitalo, K., Tuorila, H., Spector, T.D., Cherkas, L.F., Knaapila, A., Kaprio, J., et al., 2008b. The three-factor eating questionnaire, body mass index, and responses to sweet and salty fatty foods: a twin study of genetic and environmental associations. Am. J. Clin. Nutr. 88, 263-271.

Kilford, E.J., Garrett, E., Blakemore, S.J., 2016. The development of social cognition in adolescence: an integrated perspective. Neurosci. Biobehav. Rev, 70, 106-120.

Kirk, S.F., Penney, T.L., McHugh, T.L., 2009. Characterizing the obesogenic environment: the state of the evidence with directions for future research. Obes. Rev. 11, 109-117.

Koenders, P.G., van Strien, T., 2011. Emotional eating, rather than lifestyle behavior, drives weight gain in a prospective study in 1562 employees. J. Occup. Environ. Med. $53,1287-1293$.

Konttinen, H., Llewellyn, C., Silventoinen, K., Joensuu, A., Männistö, S., Salomaa, V., et al., 2018. Genetic predisposition to obesity, restrained eating and changes in body weight: a population-based prospective study. Int. J. Obes. 42, 858-865.

Konttinen, H., Llewellyn, C., Wardle, J., Silventoinen, K., Joensuu, A., Männistö, S., et al., 2015. Appetitive traits as behavioural pathways in genetic susceptibility to obesity: a population-based cross-sectional study. Sci. Rep. 14726.

Konttinen, H., van Strien, T., Männistö, S., Jousilahti, P., Haukkala, A., 2019. Depression, emotional eating and long-term weight changes: a population-based prospective study. Int. J. Behav. Nutr. Phys. Act. 16, 28.

Korkeila, M., Kaprio, J., Rissanen, A., Koskenvuo, M., 1995. Consistency and change of body mass index and weight: a study on 5967 adult Finnish twin pairs. Int. J. Obes. $19,310-317$.

Langeveld, M., DeVries, J.H., 2015. The long-term effect of energy restricted diets for treating obesity. Obesity 23, 1529-1538.

Lenard, N.R., Berthoud, H.R., 2008. Central and peripheral regulation of food intake and physical activity: pathways and genes. Obesity 16, S11-S22.

Li, J., Liu, H., Beaty, T.H., Chen, H., Caballero, B., Wang, Y., 2016. Heritability of children's dietary intakes: a population-based twin study in China. Twin Res. Hum. Genet. 19, 472-484.

Lissner, L., 2002. Measuring food intake in studies of obesity. Public Health Nutr. 5, 889-892.

Llewellyn, C.H., Trzaskowski, M., van Jaarsveld, C.H.M., Plomin, R., Wardle, J., 2014. Satiety mechanisms in genetic risk of obesity. JAMA Pediatr. 168, 338-344.

Locke, A.E., Kahali, B., Berndt, S.I., Justice, A.E., Pers, T.H., Day, F.R., et al., 2015. Genetic studies of body mass index yield new insights for obesity biology. Nature 518, 197-206.
Loos, R.J., Bouchard, C., 2008. FTO: the first gene contributing to common forms of human obesity. Obes. Rev. 9, 246-250.

Lorts, C., Adams, M.A., Tasevska, N., Tulloch, D., Yedidia, M., Hooker, S.P., OhriVachaspati, P., 2019. Community food environment moderates association between health care provider advice to lose weight and eating behaviors. Prev. Med. Rep. 22, 100926.

Lu, Y., Day, F.R., Gustafsson, S., Buchkovich, M.L., Na, J., Bataille, V., et al., 2016. New loci for body fat percentage reveal link between adiposity and cardiometabolic disease risk. Nat. Commun. 7, 10495.

Luger, M., Lafontan, M., Bes-Rastrollo, M., Winzer, E., Yumuk, V., Farpour-Lambert, N., 2017. Sugar-sweetened beverages and weight gain in children and adults: a systematic review from 2013 to 2015 and a comparison with previous studies. Obes. Facts 10, 674-693.

Maersk, M., Belza, A., Holst, J.J., Fenger-Grøn, M., Pedersen, S.B., Astrup, A., Richelsen, B., 2012. Satiety scores and satiety hormone response after sucrose-sweetened soft drink compared with isocaloric semi-skimmed milk and with non-caloric soft drink: a controlled trial. Eur. J. Clin. Nutr. 66, 523-529.

Malik, V.S., Pan, A., Willett, W.C., Hu, F.B., 2013. Sugar-sweetened beverages and weight gain in children and adults: a systematic review and meta-analysis. Am. J. Clin. Nutr. 98, 1084-1102.

Malina, R.M., Bouchard, C., Bar-Or, O., 2004. Growth, Maturation, and Physical Activity, 2nd ed. Human Kinetics, USA.

Marigorta, U.M., Gibson, G., 2014. A simulation study of gene-by-environment interactions in GWAS implies ample hidden effects. Front. Genet. 2, 225.

Marinou, K., Tousoulis, D., Antonopoulos, A.S., Stefanadi, E., Stefanadis, C., 2010. Obesity and cardiovascular disease: from pathophysiology to risk stratification. Int. J. Cardiol. 138, 3-8.

Mauriège, P., Després, J.P., Marcotte, M., Tremblay, A., Nadeau, A., Moorjani, S., et al., 1992. Adipose tissue lipolysis after long-term overfeeding in identical twins. Int. J. Obes. Relat. Metab. Disord. 16, 219-225.

McAllister, E.J., Dhurandhar, N.V., Keith, S.W., Aronne, L.J., Barger, J., Baskin, M., Benca, R.M., 2009. Ten putative contributors to the obesity epidemic. Crit. Rev. Food Sci. Nutr. 49, 868-913.

McLaren, L., 2007. Socioeconomic status and obesity. Epidemiol. Rev. 29, 29-48.

Merino, J., Dashti, H.S., Li, S.X., Sarnowski, C., Justice, A.E., Graff, M., et al., 2018. Genome-wide meta-analysis of macronutrient intake of 91,114 European ancestry participants from the cohorts for heart and aging research in genomic epidemiology consortium. Mol. Psychiatry 12, 1920-1932. https://doi.org/10.1038/s41380-0180079-4.

Mörkl, S., Lackner, S., Müller, W., Gorkiewicz, G., Kashofer, K., Oberascher, A., et al., 2017. Gut microbiota and body composition in anorexia nervosa inpatients in comparison to athletes, overweight, obese, and normal weight controls. Int. J. Eat. Disord. $50,1421-1431$.

Muniandy, M., Heinonen, S., Yki-Järvinen, H., Hakkarainen, A., Lundbom, J., Lundbom, N., et al., 2017. Gene expression profile of subcutaneous adipose tissue in BMI-discordant monozygotic twin pairs unravels molecular and clinical changes associated with sub-types of obesity. Int. J. Obes. 41, 1176-1184.

Naka, I., Furusawa, T., Kimura, R., Natsuhara, K., Yamauchi, T., Nakazawa, M., et al., 2017. A missense variant, rs373863828-A (p.Arg457Gln), of CREBRF and body mass index in Oceanic populations. J. Hum. Genet. 62, 847-849.

NCD Risk Factor Collaboration, 2017. Worldwide trends in body-mass index, underweight, overweight, and obesity from 1975 to 2016: a pooled analysis of 2416 population-based measurement studies in 128.9 million children, adolescents, and adults. Lancet 390, 2627-2642.

Neale, M.C., Hunter, M.D., Pritikin, J.N., Zahery, M., Brick, T.R., Kirkpatrick, R.M., et al, 2016. OpenMx 2.0: extended structural equation and statistical modeling. Psychometrika 81, 535-549.

Neovius, K., Johansson, K., Rössner, S., Neovius, M., 2008. Disability pension, employment and obesity status: a systematic review. Obes. Rev. 9, 572-581.

Nettleton, J.A., Follis, J.L., Ngwa, J.S., Smith, C.E., Ahmad, S., Tanaka, T., et al., 2015. Gene $\times$ dietary pattern interactions in obesity: analysis of up to 68317 adults of European ancestry. Hum. Mol. Genet. 24, 4728-4738.

Nogueira, H., Costeira E Pereira, M.M., Costa, D., Gama, A., Machado-Rodrigues, A. Silva, M.R., et al., 2019. The environment contribution to gender differences in childhood obesity and organized sports engagement. Am. J. Hum. Biol (E-pub ahead of print).

Opel, N., Redlich, R., Kaehler, C., Grotegerd, D., Dohm, K., Heindel, W., et al., 2017. Prefrontal gray matter volume mediates genetic risks for obesity. Mol. Psychiatry 22, 703-710.

Ortaga-Alomso, A., Sipilä, S., Kujala, U.M., Kaprio, J., Rantanen, T., 2009. Genetic influences on change in BMI from middle to old age: a 29-year follow-up study of twin sisters. Behav. Genet. 39, 154-164.

Ortega-Alonso, A., Pietiläinen, K.H., Silventoinen, K., Saarni, S.E., Kaprio, J., 2012. Genetic and environmental factors influencing BMI development from adolescence to young adulthood. Behav. Genet. 42, 73-85.

Paulis, W.D., Silva, S., Koes, B.W., van Middelkoop, M., 2014. Overweight and obesity are associated with musculoskeletal complaints as early as childhood: a systematic review. Obes. Rev. 15, 52-67.

Pietiläinen, K.H., Korkeila, M., Bogl, L.H., Westerterp, K.R., Yki-Järvinen, H., Kaprio, J., Rissanen, A., 2010. Inaccuracies in food and physical activity diaries of obese subjects: complementary evidence from doubly labeled water and co-twin assessments. Int. J. Obes. $34,437-445$.

Piirtola, M., Jelenkovic, A., Latvala, A., Sund, R., Honda, C., Inui, F., et al., 2018. Association of current and former smoking with body mass index: a study of smoking discordant twin pairs from 21 twin cohorts. PLoS One 13, e0200140.

Pimpin, L., Ambrosini, G.L., Llewellyn, C.H., Johnson, L., van Jaarsveld, C.H., Jebb, S.A., 
Wardle, J., 2013. Dietary intake of young twins: Nature or nurture? Am. J. Clin. Nutr. 98, 1326-1334.

Plomin, R., Deary, I.J., 2015. Genetics and intelligence differences: five special findings. Mol. Psychiatry 20, 98-108.

Poehlman, E.T., Després, J.P., Marcotte, M., Tremblay, A., Thériault, G., Bouchard, C., 1986. Genotype dependency of adaptation in adipose tissue metabolism after shortterm overfeeding. Am. J. Physiol. 250, E480-E485.

Polderman, T.J., Benyamin, B., de Leeuw, C.A., Sullivan, P.F., van Bochoven, A., Visscher, P.M., Posthuma, D., 2015. Meta-analysis of the heritability of human traits based on fifty years of twin studies. Nat. Genet. 47, 702-709.

Polubriaginof, F.C.G., Vanguri, R., Quinnies, K., Belbin, G.M., Yahi, A.S.H., 2018. Disease heritability inferred from familial relationships reported in medical records. Cell 173, 1692-1704.

Posthuma, D., Beem, A.L., de Geus, E.J., van Baal, G.C., von Hjelmborg, J.B., Iachine, I., Boomsma, D.I., 2003. Theory and practice in quantitative genetics. Twin Res. Hum. Genet. 6, 361-376.

Poveda, A., Ibáñez, M.E., Rebato, E., 2012. Heritability and genetic correlations of obesity-related phenotypes among Roma people. Ann. Hum. Biol. 39, 183-189.

Pratley, R.E., 1998. Gene-environment interactions in the pathogenesis of type 2 diabetes mellitus: lessons learned from the Pima Indians. Proc. Nutr. Soc. 57, 175-181.

Pulst, S.M., 2012. Genetic linkage analysis. Arch. Neurol. 56, 667-672.

Qi, L., Kraft, P., Hunter, D.J., Hu, F.B., 2008. The common obesity variant near MC4R gene is associated with higher intakes of total energy and dietary fat, weight change and diabetes risk in women. Hum. Mol. Genet. 17, 3502-3508.

Qi, Q., Chu, A.Y., Kang, J.H., Jensen, M.K., Curhan, G.C., Pasquale, L.R., et al., 2012. Sugar-sweetened beverages and genetic risk of obesity. N. Engl. J. Med. 367, 1387-1396.

Qi, Q., Downer, M.K., Kilpeläinen, T.O., Taal, H.R., Barton, S.J., Ntalla, I., 2015. Dietary intake, FTO genetic variants, and adiposity: a combined analysis of over 16,000 children and adolescents. Diabetes 64, 2467-2476.

Qi, Q., Chu, A.Y., Kang, J.H., Huang, J., Rose, L.M., Jensen, M.K., et al., 2014. Fried food consumption, genetic risk, and body mass index: gene-diet interaction analysis in three US cohort studies. BMJ 348, g1610.

Quetelet, L.A.J., 1994. A treatise on man and the development of his faculties. orig. 1842. Obes. Res. 2, 72-85.

Raevuori, A., Keski-Rahkonen, A., Hoek, H.W., 2014. A review of eating disorders in males. Curr. Opin. Psychiatry 27, 426-430.

Rasmussen, F., Johansson, M., 1998. The relation of weight, length and ponderal index at birth to body mass index and overweight among 18-year-old males in Sweden. Eur. J. Epidemiol. 14, 373-380.

Reddon, H., Guéant, J.L., Meyre, D., 2016. The importance of gene-environment interactions in human obesity. Clin. Sci. 130, 1571-1597.

Rice, T., Perusse, L., Bouchard, C., Rao, D.C., 1999. Familial aggregation of body mass index and subcutaneous fat measures in the longitudinal Quebec Family Study. Genet. Epidemiol. 16, 316-334.

Robinson, M.R., Hemani, G., Medina-Gomez, C., Mezzavilla, M., Esko, T., Shakhbazov, K., et al., 2015. Population genetic differentiation of height and body mass index across Europe. Nat. Genet. 47, 1357-1362.

Rokholm, B., Silventoinen, K., Angquist, L., Skytthe, A., Kyvik, K.O., Sørensen, T.I.A., 2011a. Increased genetic variance of BMI with a higher prevalence of obesity. PLoS One 6, e20816.

Rokholm, B., Silventoinen, K., Tynelius, P., Gamborg, M., Sørensen, T.I.A., Rasmussen, F., 2011b. Increasing genetic variance of body mass index during the Swedish obesity epidemic. PLoS One 6, e27135.

Rothschild, D., Weissbrod, O., Barkan, E., Kurilshikov, A., Korem, T., Zeevi, D., et al., 2018. Environment dominates over host genetics in shaping human gut microbiota. Nature 555, 210-215.

Rzehak, P., Scherag, A., Grallert, H., Sausenthaler, S., Koletzko, S., Bauer, C.P., et al., 2010. Associations between BMI and the FTO gene are age dependent: results from the GINI and LISA birth cohort studies up to age 6 years. Obes. Facts 3, 173-180.

Savage, J.S., Hoffman, L., Birch, L.L., 2009. Dieting, restraint, and disinhibition predict women's weight change over 6 y. Am. J. Clin. Nutr. 90, 33-40.

Schousboe, K., Willemsen, G., Kyvik, K.O., Mortensen, J., Boomsma, D.I., Cornes, B.K., et al., 2003. Sex differences in heritability of BMI: a comparative study of results from twin studies in eight countries. Twin Res. Hum. Genet. 6, 409-421.

Scuteri, A., Sanna, S., Chen, W.M., Uda, M., Albai, G., Strait, J., et al., 2007. Genome-wide association scan shows genetic variants in the FTO gene are associated with obesityrelated traits. PLoS Genet. 3, e115.

Seidman, D.S., Laor, A., Gale, R., Stevenson, D.K., Danon, Y.L., 1991. A longitudinal study of birth weight and being overweight in late adolescence. Am. J. Dis. Child. 145, $782-785$.

Seltzer, C.C., Mayer, J., 1966. A review of genetic and constitutional factors in human obesity. Ann. N. Y. Acad. Sci. 134, 688-695.

Silventoinen, K., Bartels, M., Posthuma, D., Estourgie- van Burk, G.F., Willemsen, G., van Beijsterveldt, T.C.E.M., Boomsma, D.I., 2007a. Genetic regulation of growth in height and weight from three to 12 years of age: a longitudinal study of Dutch twin children. Twin Res. Hum. Genet. 10, 354-363.

Silventoinen, K., Gouveia, É., Jelenkovic, A., Maia, J., Antunes, A.M., Pinheiro de Carvalho, M.A.A., et al., 2017a. The genetic background of metabolic trait clusters in children and adolescents. Metab. Syndr. Relat. Disord. 15, 329-336.

Silventoinen, K., Huppertz, C., van Beijsterveldt, C.E., Bartels, M., Willemsen, G., Boomsma, D.I., 2016a. The genetic architecture of body mass index from infancy to adulthood modified by parental education. Obesity 24, 2004-2011.

Silventoinen, K., Jelenkovic, A., Latvala, A., Yokoyama, Y., Sund, R., Sugawara, M., et al., 2019. Parental education and genetics of BMI from infancy to old age: a pooled analysis of 29 twin cohorts. Obesity $27,855-865$.
Silventoinen, K., Jelenkovic, A., Sund, R., Hur, Y., Yokoyama, Y., Honda, C., Hjelmborg, H., et al., 2016b. Genetic and environmental effects on body mass index from infancy to the onset of adulthood: an individual-based pooled analysis of 45 twin cohorts participating in the COllaborative project of development of anthropometrical measures in twins (CODATwins) study. Am. J. Clin. Nutr. 104, 371-379.

Silventoinen, K., Jelenkovic, A., Sund, R., Yokoyama, Y., Hur, Y.M., Cozen, W., et al., 2017b. Differences in genetic and environmental variation in adult body mass index by sex, age, time period, and region: an individual-based pooled analysis of 40 twin cohorts. Am. J. Clin. Nutr. 106, 457-466.

Silventoinen, K., Pietiläinen, K.H., Tynelius, P., Sørensen, T.I.A., Kaprio, J., Rasmussen, F., 2007b. Genetic and environmental factors in relative weight from birth to age 18: the Swedish Young Male Twins Study. Int. J. Obes. 31, 615-621.

Silventoinen, K., Kaprio, J., Yokoyama, Y., 2010a. Genetic regulation of pre-pubertal development of body mass index: a longitudinal study of Japanese twin boys and girls. Behav. Genet. 41, 234-241.

Silventoinen, K., Rokholm, B., Kaprio, J., Sørensen, T.I.A., 2010b. The genetic and environmental influences on childhood obesity: a systematic review of twin and adoption studies. Int. J. Obes. 34, 29-40.

Silventoinen, K., Sans, S., Tolonen, H., Monterde, D., Kuulasmaa, K., Kesteloot, H., et al., 2004. Trends in obesity and energy supply in the WHO MONICA project. Int. J. Obes. 28, 710-718. https://doi.org/10.1038/sj.ijo.0802614.

Silventoinen, K., Tatsuse, T., Martikainen, P., Rahkonen, O., Lahelma, E., Sekine, M., Lallukka, T., 2013. Occupational class differences in body mass index and weight gain in Japan and Finland. J. Epidemiol. 23, 443-450.

Sobal, J., Stunkard, A.J., 1989. Socioeconomic status and obesity: a review of the literature. Psychol. Bull. 105, 260-275.

Sørensen, T.I., Holst, C., Stunkard, A.J., 1992. Childhood body mass index-genetic and familial environmental influences assessed in a longitudinal adoption study. Int. J. Obes. 16, 705-714.

Sovio, U., Mook-Kanamori, D.O., Warrington, N.M., Lawrence, R., Briollais, L., Palmer, C.N., et al., 2011. Association between common variation at the FTO locus and changes in body mass index from infancy to late childhood: the complex nature of genetic association through growth and development. PLoS Genet. 7, e1001307.

Steinle, N.I., Hsueh, W.C., Snitker, S., Pollin, T.I., Sakul, H., St Jean, P.L., Bell, C.J., Mitchell, B.D., Shuldiner, A.R., 2002. Eating behavior in the Old Order Amish: heritability analysis and a genome-wide linkage analysis. Am. J. Clin. Nutr. 75, 1098-1106.

Steinsbekk, S., Belsky, D., Guzey, I.C., Wardle, J., Wichstrøm, L., 2016. Polygenic risk, appetite traits, and weight gain in middle childhood: a longitudinal study. JAMA Pediatr. 170, e154472.

Stunkard, A.J., Foch, T.T., Hrubec, Z., 1986a. A twin study of human obesity. JAMA 256, 51-54.

Stunkard, A.J., Messick, S., 1985. The three-factor eating questionnaire to measure dietary restraint, disinhibition and hunger. J. Psychosom. Res. 29, 71-83.

Stunkard, A.J., Sorensen, T.I., Hanis, C., Teasdale, T.W., Chakraborty, R., Schull, W.J. Schulsinger, F., 1986b. An adoption study of human obesity. N. Engl. J. Med. 314, 193-198.

Stutzmann, F., Cauchi, S., Durand, E., Calvacanti-Proença, C., Pigeyre, M., Hartikainen, A.L., et al., 2009. Common genetic variation near MC4R is associated with eating behaviour patterns in European populations. Int. J. Obes. 33, 373-378.

Tanofsky-Kraff, M., Han, J.C., Anandalingam, K., Shomaker, L.B., Columbo, K.M., Wolkoff, L.E., et al., 2009. The FTO gene rs9939609 obesity-risk allele and loss of control over eating. Am. J. Clin. Nutr. 90, 1483-1488.

Tarnoki, A.D., Tarnoki, D.L., Bogl, L.H., Medda, E., Fagnani, C., Nisticò, L., et al., 2013. Association of body mass index with arterial stiffness and blood pressure components: a twin study. Atherosclerosis 229, 388-395.

Tchernof, A., Després, J.P., 2013. Pathophysiology of human visceral obesity: an update. Physiol. Rev. 93, 359-404.

Teucher, B., Skinner, J., Skidmore, P.M., Cassidy, A., Fairweather-Tait, S.J., Hooper, L., Roe, M.A., et al., 2007. Dietary patterns and heritability of food choice in a UK female twin cohort. Twin Res. Hum. Genet. 10, 734-748.

Tholin, S., Rasmussen, F., Tynelius, P., Karlsson, J., 2005. Genetic and environmental influences on eating behavior: the swedish young male twins study. Am. J. Clin. Nutr. $81,564-569$.

Thornton, L.M., Mazzeo, S.E., Bulik, C.M., 2011. The heritability of eating disorders: methods and current findings. In: Adan, R.A.H., Kaye, W.H. (Eds.), Behavioral Neurobiology of Eating Disorders. Springer, Heidelberg, pp. 141-156.

Turcot, V., Lu, Y., Highland, H.M., Schurmann, C., Justice, A.E., Fine, R.S., et al., 2018. Protein-altering variants associated with body mass index implicate pathways that control energy intake and expenditure in obesity. Nat. Genet. 50, 26-41.

Tyrrell, J., Wood, A.R., Ames, R.M., Yaghootkar, H., Beaumont, R.N., Jones, S.E., et al., 2017. Gene-obesogenic environment interactions in the UK biobank study. Int. J. Epidemiol. 46, 559-575.

van den Bree, M.B., Eaves, L.J., Dwyer, J.T., 1999. Genetic and environmental influences on eating patterns of twins aged $\& /=50$ y. Am. J. Clin. Nutr. 70, 456-465.

Vazquez, G., Duval, S., Jacobs Jr., D.R., Silventoinen, K., 2007. Comparison of body mass index, waist circumference, and waist/hip ratio in predicting incident diabetes: a meta-analysis. Epidemiol. Rev. 29, 115-128.

Vucenik, I., Stains, J.P., 2012. Obesity and cancer risk: evidence, mechanisms, and recommendations. Ann. N. Y. Acad. Sci. 1271, 37-43.

Wainschtein, P., Jain, D.O., Yengo, L., Zheng, Z., TOPMed Anthropometry Working Group, Trans-Omics for Precision Medicine Consortium, Cupples, L.A., 2019. Recovery of trait heritability from whole genome sequence data. bioRxiv. https://doi. org/10.1101/588020.

Wajchenberg, B.L., 2000. Subcutaneous and visceral adipose tissue: their relation to the metabolic syndrome. Endocr. Rev. 21, 697-738. 
Wardle, J., Llewellyn, C., Sanderson, S., Plomin, R., 2009. The FTO gene and measured food intake in children. Int. J. Obes. 33, 42-45.

Warrington, N.M., Howe, L.D., Paternoster, L., Kaakinen, M., Herrala, S., Huikari, V., et al., 2015. A genome-wide association study of body mass index across early life and childhood. Int. J. Epidemiol. 44, 700-712.

Watson, H.J., Yilmaz, Z., Thornton, L.M., Hübel, C., Coleman, J.R.I., Gaspar, H.A., et al., 2019. Genome-wide association study identifies eight risk loci and implicates metabo-psychiatric origins for anorexia nervosa. Nat. Genet. 51, 1207-1214.

Weise, C.M., Bachmann, T., Pleger, B., 2019. Brain structural differences in monozygotic twins discordant for body mass index. Neuroimage 201, 116006.

Wen, W., Zheng, W., Okada, Y., Takeuchi, F., Tabara, Y., Hwang, J.Y., Dorajoo, R., 2014. Meta-analysis of genome-wide association studies in East Asian-ancestry populations identifies four new loci for body mass index. Hum. Mol. Genet. 23, 5492-5504.

Wilson, M.E., Fisher, J., Fischer, A., Lee, V., Harris, R.B., Bartness, T.J., 2008. Quantifying food intake in socially housed monkeys: social status effects on caloric consumption. Physiol. Behav. 94, 586-594.

Withers, R.F.J., 1964. Problems in the genetics of human obesity. Eugen. Rev. 56, 81-90. Withrow, D., Alter, D.A., 2011. The economic burden of obesity worldwide: a systematic review of the direct costs of obesity. Obes. Rev. 12, 131-141.

Wu, C., Gong, Y., Yuan, J., Gong, H., Zou, Y., Ge, J., 2012. Identification of shared genetic susceptibility locus for coronary artery disease, type 2 diabetes and obesity: a metaanalysis of genome-wide studies. Cardiovasc. Diabetol. 11, 68. https://doi.org/10. 1186/1475-2840-11-68.

Yengo, L., Sidorenko, J., Kemper, K.E., Zheng, Z., Wood, A.R., Weedon, M.N., et al., 2018. Meta-analysis of genome-wide association studies for height and body mass index in 700000 individuals of European ancestry. Hum. Mol. Genet. 27, 3641-3649.

Zobel, E.H., Hansen, T.W., Rossing, P., von Scholten, B.J., 2016. Global changes in food supply and the obesity epidemic. Curr. Obes. Rep. 5, 449-455. 